\title{
Novel proteinase-activated receptor-2 (PAR2) antagonist C391 blocks Alternaria-induced human airway epithelial signaling and asthma indicators in murine models
}

Candy Rivas ${ }^{1}$, Michael Yee ${ }^{2}$, Kenneth Addison ${ }^{1}$, Marissa Lovett ${ }^{1}$, Kasturi Pal ${ }^{2}$, Julie Ledford $^{3}$, Greg Dussor ${ }^{4}$, Theodore Price ${ }^{4}$, Josef Vagner ${ }^{5}$, Kathryn DeFea ${ }^{2}$, and Scott Boitano ${ }^{1}$

${ }^{1}$ The University of Arizona Arizona Health Sciences Center

${ }^{2}$ University of California Riverside School of Medicine

${ }^{3}$ University of Arizona Medical Center - University Campus

${ }^{4}$ The University of Texas at Dallas School of Behavioral and Brain Sciences

${ }^{5}$ The University of Arizona BIO5 Institute

September 24, 2021

\begin{abstract}
Background and Purpose: Despite availability of a variety of treatment options, many asthma patients have poorly controlled disease with frequent exacerbations. Proteinase-activated receptor-2 (PAR2) has been identified in pre-clinical animal models as important to asthma initiation and progression following allergen exposure. Proteinase activation of PAR2 induces intracellular $\mathrm{Ca} 2+$, mitogen activated protein kinase (MAPK) and ?-arrestin signaling the airway, leading to both inflammatory and protective effects. We have developed C391, a potent PAR2 antagonist effective in blocking peptidomimetic- and trypsin-induced PAR2 signaling in vitro as well as reducing inflammatory PAR2-associated pain in vivo. We hypothesized that PAR2 reduction with C391 would attenuate allergen-induced asthma indicators in murine models. Experimental Approach: We evaluated the ability for C391 to alter Alternaria alternata-induced PAR2 signaling pathways in vitro using a human airway epithelial cell line that naturally expresses PAR2 (16HBE14o-) and a transfected embryonic cell line (HEK 293). We next evaluated the ability for C391 to reduce A. alternata-induced asthma indicators in vivo in two murine strains. Key Results: C391 blocked A. alternata-induced, PAR2-dependent Ca2+ and MAPK signaling in 16HBE14o- cells, as well as ?-arrestin recruitment in HEK 293 cells. C391 effectively attenuated A. alternata-induced inflammation, mucus production, mucus cell hyperplasia and airway hyperresponsiveness in acute asthma murine models. Conclusions and Implications: To our knowledge, this is the first demonstration of pharmacological intervention of PAR2 to reduce allergen-induced asthma indicators in vivo. These data support further development of PAR2 antagonists as potential first-in-class allergic asthma drugs.
\end{abstract}

Title: Novel proteinase-activated receptor-2 (PAR2) antagonist C391 inhibits Alternaria -induced human airway epithelial signaling and asthma indicators in murine models

Running Title: Inhibition of PAR2 signaling in allergen-induced asthma

Authors: Candy M. Rivas ${ }^{1,2}$, Michael C. Yee ${ }^{3}$, Kenneth J. Addison ${ }^{2,4}$, Marissa Lovett ${ }^{1}$, Kasturi Pal ${ }^{3}$, Julie G. Ledford ${ }^{2,4}$, Gregory Dussor ${ }^{5}$, Theodore J. Price ${ }^{5}$, Josef Vagner ${ }^{6}$, Kathryn A. DeFea ${ }^{3}{ }^{7}$ and Scott Boitano*1,2,4,6, 8

${ }^{1}$ University of Arizona Physiological Sciences Graduate Interdisciplinary Program

${ }^{2}$ University of Arizona Heath Sciences, Asthma and Airway Disease Research Center 
${ }^{3}$ University of California Riverside, Biomedical Sciences

${ }^{4}$ University of Arizona Heath Sciences, Department of Cellular and Molecular Medicine

${ }^{5}$ University of Texas at Dallas, School of Behavioral and Brain Sciences and Center for Advanced Pain Studies

${ }^{6}$ University of Arizona Bio5 Collaborative Research Institute

${ }^{7}$ PARMedics, Inc.

${ }^{8}$ University of Arizona Heath Sciences, Department of Physiology

*Corresponding Author : Kathryn A. DeFea, Ph.D.; CEO, PARMedics Inc.; 41593 Winchester Rd. Suite 228, Temecula, CA, 92590 and Professor Emeritus, Biomedical Sciences, University of California Riverside; Riverside, CA, 92521 kdefea@parmedics.com, +1-925-967-2363

Author Contributions: CMR: experimental design, experiments, manuscript writing and editing; MCY: conducted experiments and data analysis, manuscript editing; KJA: experiments and data analysis; ML: conducted experiments and data analysis; KP: conducted experiments and data analysis; JGL; experimental design, manuscript editing; GD: experimental design, manuscript editing; TJP: experimental design, data analysis, manuscript writing and editing; JV: experimental design, data analysis and manuscript editing; KAD: experimental design, data analysis, manuscript writing and editing; SB: experimental design, experiments, data analysis, manuscript writing, and editing

Word Count : 6187

Acknowledgements : We would like to thank Dr. Kim Barrett for her guidance in helping to prepare the manuscript. This work was funded in part through grants from the National Institute of Health grants (NINDS NS098826 SB, TJP, JV, GD; NIAID AI140257 SB). CMR was an American Physiological Society William H. Townsend Porter Pre-doctoral Fellow.

Competing Interests : There are no competing interests.

Abbreviations:

16HBE14o- cells - an SV40-transformed human bronchial epithelial cell line

2at-LIGRL-NH $\mathrm{N}_{2}$ - 2-aminothiazole-LIGR-NH 2 , a PAR2 agonist

2f-LIGRLO-NH $\mathrm{N}_{2}$ - 2-furoyl-LIGRLO-NH${ }_{2}$, a PAR2 agonist

AEBSF - 4-(2-aminoethyl)benzenesulfonyl fluoride hydrochloride, a serine proteinase inhibitor

AC-55541 - PAR2 antagonist

AC-264613 - PAR2 antagonist

AZ8838 - PAR2 antagonist

AZ3451 - PAR2 antagonist

BRET - bioluminescence resonance energy transfer

C391 - compound 391, a PAR2 antagonist

$\left[\mathrm{Ca}^{2+}\right]_{\mathrm{i}}$ - Intracellular $\mathrm{Ca}^{2+}$ concentration

CPMCRI - California Pacific Medical Center Research Institute

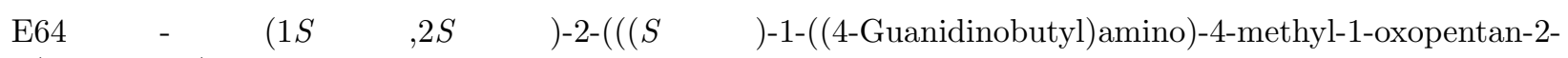
yl)carbamoyl)cyclopropanecarboxylic acid, a cysteine proteinase inhibitor

GB88 - PAR2 antagonist 
$\mathrm{H} \& \mathrm{E}$ - haematoxylin and eosin stain

HEK 293 - human embryonic kidney cell line

ICW - In Cell Western

K-14585 - PAR2 antagonist

LHC - Lechner and LaVeck basal medium

Luc - Luciferase

MAPK - mitogen activated protein kinase

Max Rrs - maximum total airway resistance

MCS - Matrix coating solution

MEM - Minimal essential medium

p-MAPK - phosphorylated MAPK

PAR2 - proteinase-activated receptor-2

PAS - Periodic Acid Schiff

PAR2 $^{-/-}$- PAR2 knockout animals

YFP - Yellow fluorescent protein

\section{Bullet Point Summary}

\section{What is already known:}

Asthma is a prevalent and growing disease with limited pharmacological treatments that focus on symptom relief

Proteinase activated receptor-2 (PAR2) knockout models suggest that PAR2 is a novel target for asthma treatment

\section{What this study adds}

C391 is a potent PAR2 antagonist that limits asthma allergen (Alternaria alternata) -induced $\mathrm{Ca}^{2+}$, MAPK and $\beta$-arrestin cellular signaling in vitro

C391 prophylactically limits $A$. alternata -induced asthma indicators in acute exposure murine models of asthma

\section{Clinical Significance}

This is the first indication of pharmacological control of allergen-induced asthma response via PAR2 small molecule antagonism in pre-clinical models

Further development of PAR2 antagonists may provide novel treatments for allergic asthma

\section{Abstract and Keywords}

Background and Purpose : Despite availability of a variety of treatment options, many asthma patients have poorly controlled disease with frequent exacerbations. Proteinase-activated receptor-2 (PAR2) has been identified in pre-clinical animal models as important to asthma initiation and progression following allergen exposure. Proteinase activation of PAR2 induces intracellular $\mathrm{Ca}^{2+}$, mitogen activated protein kinase (MAPK) and $\beta$-arrestin signaling the airway, leading to both inflammatory and protective effects. We have developed C391, a potent PAR2 antagonist effective in blocking peptidomimetic- and trypsin-induced 
PAR2 signaling in vitro as well as reducing inflammatory PAR2-associated pain in vivo. We hypothesized that PAR2 reduction with C391 would attenuate allergen-induced asthma indicators in murine models.

Experimental Approach : We evaluated the ability for C391 to alter Alternaria alternata -induced PAR2 signaling pathwaysin vitro using a human airway epithelial cell line that naturally expresses PAR2 (16HBE14o-) and a transfected embryonic cell line (HEK 293). We next evaluated the ability for C391 to reduce $A$. alternata -induced asthma indicators in vivo in two murine strains.

Key Results : C391 blocked A. alternata -induced, PAR2-dependent $\mathrm{Ca}^{2+}$ and MAPK signaling in 16HBE14o- cells, as well as $\beta$-arrestin recruitment in HEK 293 cells. C391 effectively attenuated A. alternata -induced inflammation, mucus production, mucus cell hyperplasia and airway hyperresponsiveness in acute asthma murine models.

Conclusions and Implications : To our knowledge, this is the first demonstration of pharmacological intervention of PAR2 to reduce allergen-induced asthma indicators in vivo . These data support further development of PAR2 antagonists as potential first-in-class allergic asthma drugs.

Key Words : Airway Inflammation; Airway Hyperresponsiveness; Allergen-induced asthma; Alternaria alternata ; C391; Mucus cell hyperplasia; PAR2;

\section{Main Text}

\section{Introduction:}

Asthma is a common and growing lung disease afflicting the world population (Martinez \& Vercelli, 2013; To et al., 2012). While there is no cure, many therapeutic options have been successfully used to control mildto-moderate asthma symptoms for the past 60 years. The most commonly-prescribed asthma medications include bronchodilators composed of aerosolized $\beta$-adrenergic agonists or cholinergic antagonists, and antiinflammatory medicines such as corticosteroids, anti-leukotrienes, and monoclonal antibodies (Stephenson et al., 2016). Despite the seeming plethora of treatment options to control asthma, approximately $50 \%$ of asthmatics with moderate to severe disease do not have adequate control of their symptoms (Martinez \& Vercelli, 2013).

Allergic asthma can be triggered by a variety of environmental factors including exposure to the ubiquitous fungus Alternaria alternata. A. alternata is a prominent fungal allergen that has been associated with increased asthma-related hospitalization in children, and homes with higher levels of A. Alternata reported a higher incidence of moderate to severe asthma (Batra et al., 2021; Bush \& Prochnau, 2004; Halonen, Stern, Wright, Taussig \& Martinez, 1997; Lombardi, Savi, Ridolo, Passalacqua \& Canonica, 2017; Mendy, Wilkerson, Salo, Zeldin \& Thorne, 2020; Pulimood, Corden, Bryden, Sharples \& Nasser, 2007). When found in semi-arid regions, A alternata contains a proteinase, Alternaria alkaline Serine Proteinase (AASP), that acts through the G-protein-coupled receptor (GPCR), proteinase-activated-receptor-2 (PAR2), to induce airway inflammation, mucus production and bronchoconstriction (Boitano et al., 2011; Snelgrove et al., 2014; Yee et al., 2018). Trypsin-like serine proteinases associated with other allergy-inducing pathogens such as cockroach and house dust mite also activate PAR2 to promote airway inflammation [e.g., (Adam et al., 2006; Page, Ledford, Zhou, Dienger \& Wills-Karp, 2010; Polley et al., 2017)]. Studies using PAR2 knockout (PAR2-/-) animals have demonstrated that PAR2 expression is critical for allergen-induced asthma indicators (Arizmendi et al., 2011; Davidson et al., 2013; Day, Zhou, Ledford \& Page, 2010; Page, Ledford, Zhou, Dienger \& Wills-Karp, 2010; Yee et al., 2018). Further, studies using PAR2-neutralizing antibodies have demonstrated a reduction in allergen-induced asthma indicators in both acute and chronic allergen-exposed animal models (Asaduzzaman, Davidson, Nahirney, Fiteih, Puttagunta \& Vliagoftis, 2018; Asaduzzaman et al., 2015). Collectively, PAR2 has emerged as a viable drug target for the treatment of asthma (Ramachandran, Noorbakhsh, Defea \& Hollenberg, 2012).

A common approach to developing novel GPCR drugs is via screening of large libraries, however, this approach has had limited success with PAR2 ligands (Cheng et al., 2017; Gardell et al., 2008). An alternative

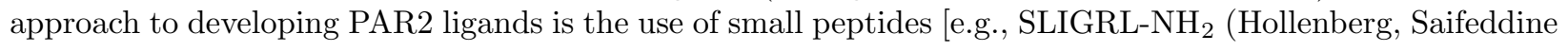


\& al-Ani, 1996)] or peptidomimetics [e.g., 2-furoyl-LIGRLO-NH ${ }_{2}$; (McGuire, Saifeddine, Triggle, Sun \& Hollenberg, 2004)] that mimic the activating peptide sequence following proteolytic cleavage of the receptor (Ramachandran \& Hollenberg, 2008; Yau, Liu \& Fairlie, 2013). A more recent advance from our laboratory is the modification of the peptide sequence of the high potency peptidomimetic PAR2 agonist, 2-furoylLIGRLO-NH $\mathrm{N}_{2}$, to form a novel PAR2 antagonist pharmacophore, compound 391 [C391; (Boitano et al., 2015)]. C391 is one of a handful of recently proposed PAR2 antagonists (Avet et al., 2020; Cheng et al., 2017; Goh, Ng, Nilsson, Kanke \& Plevin, 2009; Hollenberg et al., 2014; Huang, Ni, Xi, Chu, Zhang \& You, 2019; Kanke et al., 2005; Suen et al., 2012; Suen et al., 2014; Yau, Lim, Liu \& Fairlie, 2016). It is distinct from other reported antagonists in that it requires minimal pre-incubation for inhibition of peptide activation of PAR2-dependent $\mathrm{Ca}^{2+}$ signaling and it acts as an antagonist for mitogen activating protein kinase (MAPK) signaling pathways. Further, C391 is one of the only known antagonists shown to be effective in blocking both natural proteinase and peptidomimetic activation of PAR2 in vitro and to be effective for blocking pain response in vivo (Boitano et al., 2015).

In this study we sought to evaluate the ability of C391 to inhibit allergen-induced, PAR2-dependent signaling in airway epithelial cells, and asthma indicators in murine models. We hypothesized that C391 would be effective at protecting against the development of cellular inflammation and broncho-constriction in preclinical asthma models. To this endeavor we first used established cellular models to demonstrate that C391 reduced or eliminated $A$. alternata -induced $\mathrm{Ca}^{2+}$ mobilization, $\beta$-arrestin recruitment and MAPK activation. Finally, we demonstrated that C391 was able to reduce or eliminate A alternata -induced asthma indicators (inflammation, mucus production and airway hyperresponsiveness) in acutely-exposed murine models. These experiments demonstrate the ability of C391 to alter multiple allergen-induced and PAR2-dependent signaling pathwaysin vitro and demonstrate the first successful pharmacological reduction of asthma indicators in a pre-clinical model. Taken together, these data further support PAR2 as a druggable target to control allergen-induced asthma.

\section{Materials and Methods}

Materials

Alternaria alternata filtrate was purchased from Stallergenes Greer Laboratories (Lenoir, NC). PAR2 agonists [2-aminothiazole-LIGR- $\mathrm{NH}_{2}($ 2at-LIGRL-NH$)$ and 2-furoyl-LIGRLO-NH 2 (2f-LIGRLO- $\left.\mathrm{NH}_{2}\right)$ ], and the PAR2 antagonist C391 were manufactured in our laboratory as described (Boitano et al., 2011; Boitano et al., 2015; Flynn et al., 2011; Hoffman et al., 2012). Unless listed below, all other chemicals/components were of Molecular Biology or higher grades and purchased from Fisher Scientific (Pittsburgh, PA), ThermoFisher Scientific (Watham, MA), Sigma-Aldrich (Burlington, MA), or VWR (West Chester, PA).

\section{Cellular Studies}

16HBE14o- cells. 16HBE14o- cells are a SV40-transformed human bronchial epithelial cell line (Gruenert, Finkbeiner \& Widdicombe, 1995) obtained from the California Pacific Medical Center Research Institute (CPMCRI; San Francisco, CA, USA) that naturally express PAR2 and thus provide an experimental cellular model for evaluating PAR2 agonism and antagonism. 16HBE14o- cells were passaged as suggested by CPMCRI. Cells were expanded in tissue culture flasks prior to transfer to cultureware for specific experiments. Flasks were coated initially with a matrix coating solution [MCS; 88\% LHC (Lechner and LaVeck) basal medium, $10 \%$ bovine serum albumin (BSA; from $1 \mathrm{mg} / \mathrm{ml}$ stock), $1 \%$ bovine collagen type I (from $2.9 \mathrm{mg} / \mathrm{ml}$ stock), and $1 \%$ human fibronectin (from $1 \mathrm{mg} / \mathrm{ml}$ stock solution)] and incubated for two hrs at $37^{\circ} \mathrm{C}$, after which the MCS was removed and the flasks allowed to dry for at least one hr. 16HBE14o- cells were plated onto the MCS-coated cultureware at a density of $1 \times 10^{5} \mathrm{cells} / \mathrm{cm}^{2} .16 \mathrm{HBE} 14 \mathrm{o}-$ cells were cultured in Eagles minimal essential medium with Earle's salts supplemented with 10\% FBS, $2 \mathrm{mM}$ glutamax, penicillin and streptomycin (MEM) at $37^{\circ} \mathrm{C}$ in a $5 \% \mathrm{CO}_{2}$ atmosphere. Medium was replaced every other day until the cells reached confluence ( 5 - 7 days). Cells were then transferred to appropriate MCS-coated substrate for analyses.

Alternaria alternata filtrate. A. alternatafiltrate was purchased as a lyophilized powder (Stallergenes 
Greer \#XPM1D3A), resuspended in HBSS, vortexed and stored at $2.5 \mathrm{mg} / \mathrm{mL}$ protein at $-20^{\circ} \mathrm{C}$ until experimental use. Proteinase content for each lot was determined prior to use; activity of the filtrate used in this study was comparable to $6.5 \mathrm{U} / \mathrm{mL}$ trypsin activity (Sigma \#T6567; 13,190 U/mg) as determined with a commercial proteinase assay kit (Sigma \#PF-0100).

$\mathrm{Ca}^{2+}$ signaling measurements . Intracellular $\mathrm{Ca}^{2+}$ concentrations $\left(\left[\mathrm{Ca}^{2+}\right]_{\mathrm{i}}\right)$ were measured using digital imaging microscopy as described (Boitano et al., 2011; Boitano et al., 2015). 16HBE14o- cells were plated onto MCS-coated $15 \mathrm{~mm}$ glass coverslips and grown to confluence. Coverslip cultures were washed with HBSS and loaded for 45 min with $5 \mu \mathrm{M}$ fura 2-acetomethoxy ester (fura 2-AM) in HBSS and then transferred to HBSS for 30 min before imaging. Fura 2 fluorescence was observed on an Olympus IX70 microscope with a $40 \times$ oil immersion objective (corrected for UV light) after alternating excitation between $340 \mathrm{~nm}$ and 380 $\mathrm{nm}$ by a $75 \mathrm{~W}$ Xenon lamp linked to a Delta Ram V illuminator (PTI, London, Ontario, Canada) via a gel optic line. $\left[\mathrm{Ca}^{2+}\right]_{\mathrm{i}}$ for each individual cell in the field of view was calculated by ratiometric analysis of fura 2 fluorescence using equations originally published in (Grynkiewicz, Poenie \& Tsien, 1985). For verification of A. alternata, ATP (Sigma A2383) or Thrombin (Sigma 10602400001; $20 \mathrm{U} / 22.23 \mathrm{mg}$ protein) agonist activity, fura 2-loaded cells were monitored for 20 sec in HBSS to record baseline $\left[\mathrm{Ca}^{2+}\right]_{\mathrm{i}}$ followed by a 10 sec wash to introduce agonist and an additional $2 \mathrm{~min} 30 \mathrm{sec}$ of monitoring for agonist-induced changes in $\left[\mathrm{Ca}^{2+}\right]_{\mathrm{i}}$. For C391 antagonism (A. alternata ) or control (ATP or Thrombin) experiments, a similar protocol was used with a 2 min incubation with C391 dispensed after the 20 sec baseline measurement and with the agonist solution containing an identical concentration of C391. Individual ratios $(\sim 1 / \mathrm{sec})$ were calculated throughout the 3 - or 5 -min experiments. $\left[\mathrm{Ca}^{2+}\right]_{\mathrm{i}}$ traces over time were represented as average $\left[\mathrm{Ca}^{2+}\right]_{\mathrm{i}}$ of all cells within a field of view $(\sim 80-100)$ and are representative of at least 4 experiments. Color maps of $A$. alternaria responses (+/- C391) were constructed using Adobe Photoshop (Cupertino, CA) and indicate approximate $\left[\mathrm{Ca}^{2+}\right]_{\mathrm{i}}$ of individual cells at given time in the experiment.

Detection of MAPK Signaling/In-Cell Western (ICW). ICW studies were adapted from methods described in (Flynn et al., 2011). 16HBE14o- cells were plated onto MCS-treated, clear bottom, black-walled 96-well plates at a density of $2 \times 10^{4}$ cells per well. Cells were allowed to reach confluence (3 - 4 days of growth) and were subsequently serum-starved overnight in MEM supplemented with $10 \mu \mathrm{M}$ AEBSF and $10 \mu \mathrm{M}$ E64. On the following day, cells were treated with C391 suspended in MEM to a final concentration of $1 \times$ (final concentration range of $100 \mathrm{nM}-100 \mu \mathrm{M}$ C391) and cells were incubated for $15 \mathrm{~min}$. This was followed by a treatment of equal volumes of $A$. alternata (final concentration of $20 \mu \mathrm{g} / \mathrm{mL} ; 2 \mathrm{U} / \mathrm{mL}$ trypsin activity) mixed with $1 \times$ final C391 concentration. After 5 min, cells were fixed with $4 \%$ paraformaldehyde and permeabilized with $100 \%$ methyl alcohol. Fixed cells were incubated with blocking buffer ( $5 \%$ goat serum, $0.3 \%$ Triton X100) prior to incubation with primary phosphorylated MAPK antibody (p-MAPK; rabbit anti-mouse p-ERK; \#9101 Cell Signaling Technologies, Grand Island, NY), secondary antibody (goat anti-rabbit DyLight; \#5151 Cell Signaling Technologies) and nuclear stain DRAQ5 (\#4804, Cell Signaling Technologies). Plates were imaged on an Odyssey Scanner (LI-COR, Lincoln, NE) following the manufacturer's protocol. p-MAPK levels were normalized to DRAQ5 content and data are presented as percent above the MEM-treated (baseline) control. $\mathrm{IC}_{50} \mathrm{~s}$ were determined using a 4-parameter curve fit, with hill slopes constrained to one, with GraphPad Prizm software (San Diego, CA).

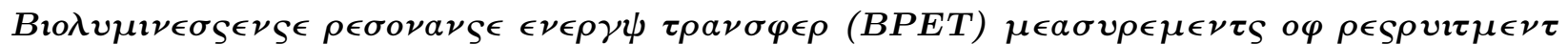
$o \varphi \beta$ - $\boldsymbol{\rho} \rho \rho \epsilon \sigma \tau \imath \nu-2$. Competitive BRET measurements with A. alternata $(65 \mu \mathrm{g} / \mathrm{mL} ; 6.5$ trypsin U/mL) and C391 (concentration range; $100 \mathrm{pM}-100 \mu \mathrm{M}$ ) were adapted from (Yee et al., 2018). Briefly, HEK 293 cells transfected with PAR2-YFP and Luciferase (Luc) tagged $\beta$-arrestin-2 were plated in 96-well microplates and $A$. alternata (w/without C391) was added along with the Luc substrate coelenterazine. Readings were collected using a Multilabel Reader Tristar9640 (Berthold, Bad Wildbad, Germany) and emission was detected at $480 \mathrm{~nm}$ (Luc) and $535 \mathrm{~nm}$ (YFP). Net BRET was determined from the ratio of emission in the YFP channel to the emission in the luciferase channel (E535/E488) minus the donor-only ( $\beta$-arrestinLuc) control values. To eliminate possibility that observed signals represented non-specific interactions, we included a $\beta$-arrestin-Luc + YFP in every experimental condition, which gave values similar to donor only controls. Data points were fitted to a curve and $\mathrm{IC}_{50}$ calculated using a 4-parameter curve fit, with hill 
slopes constrained to one, with GraphPad Prizm (San Diego, CA).

Animal Studies: All animal procedures were in accordance with the guidelines on the use and care of laboratory animals set by the National Institutes of Health and approved by the Institutional Animal Care and Use Committees at the University of California, Riverside, or the University of Arizona and in accordance with ARRIVE andBritish Journal of Pharmacology guidelines. Wild type C57Bl/6J (\#000664) and BALB/c mice (\#000651) were purchased from The Jackson Laboratory (Bar Harbor, ME). C57Bl/6 animals were bred in-house. Animals used in these studies were male, between 6 and 10 weeks of age. Male mice were used due to the unknown effects of cycling estradiol on airway inflammation and asthma. On days 0,3 and 7, $\mathrm{C} 57 \mathrm{Bl} / 6$ mice ( 8 - 10 weeks old at day 0 ), were sedated under brief ketamine anesthesia and intranasally exposed to one of the following: $25 \mu \mathrm{L}$ of HBSS control, $8 \mu \mathrm{g}$ of $A$. alternata filtrate in HBSS; or $8 \mu \mathrm{g}$ of $A$. alternata filtrate supplemented with 0.25 nmoles or 2.5 nmoles of C391. For BALB/c mice, $50 \mu \mathrm{L}$ of HBSS control; $5 \mu \mathrm{g}$ of A. alternatafiltrate in HBSS; or $5 \mu \mathrm{g}$ of A. alternata filtrate supplemented with 5 nmoles C391 was administered on days 0, 3 and 7 under isoflurane anesthesia. Assessment of asthma indicators was performed on day 8 for both murine models. Each experiment contained a minimum of 2 repeats with 3 animals in each group. Mice were assigned randomly to groups. Specific numbers for each experiment are listed in the text and/or Figure Legends.

Airway hyperresponsiveness in A. alternata-treated $\boldsymbol{B A L B} / \boldsymbol{c}$ mice: On day 8 direct measurements of respiratory mechanics in response to methacholine were obtained with the use of the Flexivent system (SCIREQ Inc., Montreal, Qc Canada) adapted from procedures previously used in our laboratory (Addison, Morse, Robichaud, Daines \& Ledford, 2017). Briefly, mice were anesthetized with an intraperitoneal injection of urethane in sterile $\mathrm{H}_{2} \mathrm{O}(125 \mathrm{mg} / \mathrm{mL})$ at a final dose of $16 \mu \mathrm{L} /$ gram of body weight. The average mouse weighed $25 \mathrm{~g}$ and thus received $400 \mu \mathrm{L}$ of urethane. Once a surgical plane of anesthesia was reached, the trachea of the mouse was fit with a 19-gauge metal cannula and subsequently ventilated with a computercontrolled small animal ventilator with a tidal volume of $7.5 \mathrm{mg} / \mathrm{kg}$ and a positive end-expiratory pressure of $3 \mathrm{~cm} \mathrm{H}_{2} \mathrm{O}$. The mice were given a muscular paralytic (pancuronium bromide; Sigma \#P1918) solubilized in saline $(0.8 \mathrm{mg} / \mathrm{mL})$ and administered at a final dose of $10 \mu \mathrm{L} /$ gram of body weight to eliminate any breathing interference in the recordings. A $25 \mathrm{~g}$ mouse would receive $250 \mu \mathrm{L}$ of pancuronium bromide. Respiratory mechanics were obtained by the forced oscillation technique; values were reported as total pulmonary resistance $(\mathrm{RT}) \mathrm{cm} \mathrm{H}_{2} \mathrm{O} / \mathrm{mL} / \mathrm{s}$. Mice were sacrificed after completion of these experiments for examination of cellular inflammation.

Histochemical and inflammation analyses in A. alternata-treated mice: Bronchioalveolar lavage fluid (BALF) was collected in 1-5 mLs of PBS after which lungs were removed, fixed in $10 \%$ formalin and stored in $70 \%$ ethanol until paraffin embedding. Paraffin embedded $\mathrm{C} 57 \mathrm{Bl} / 6$ lung sections were stained with hematoxylin and eosin (H\&E) or Alcian Blue [to stain acidic mucins; (\#AFR-1-IFU Scytek Laboratories, Logan, UT)]. Sections were imaged using a Nikkon Eclipse E600 microscope with 10X air or 40X oil immersion objectives, using a PAXcam microscope camera and PAXIT! Software (Villa Park, IL). Ethanol-preserved Balb/c lungs were sent to AML Laboratories (St. Augustine, FL) for processing (paraffin embedding; 4 $\mu \mathrm{m}$ sections) and stained (H\&E or Periodic Acid Schiff (PAS) as the mucin stain). Sections were imaged using an Olympus IX70 inverted microscope and $20 \times$ air or $60 \times$ oil immersion objectives. Images were captured using a MicroPublisher 6 camera (QImaging, Tucson). A. alternata includes a variety of allergenic proteins (e.g., Alt a 10, chitin, particulates and proteinases), but our previous studies indicate that PAR2activating serine-proteinase(s) from Alternaria are essential for the observed airway inflammation, goblet cell hyperplasia and mucus overproduction (Boitano et al., 2011; Yee et al., 2018)., AZ). Semi-quantitative scoring of inflammation and mucin staining was performed by histological grading as previously described (Nichols et al., 2012), based on infiltration of white blood cells and perivascular thickness. using a scoring scale of $1-4$, with 1 being no inflammation present, 2 being 1 ring of leukocytes around the vasculature and mild infiltration, 3 being 2 - 3 rings and moderate infiltration, and 4 being 4 or more rings and numerous leukocytes throughout the epithelial tissue (Zeldin et al., 2001). Epithelial thickness was quantified using NIH Image J to measure the distance from the basolateral surface of the epithelial cell to the muscular layer. Mucin positive cells were quantified in Alcian Blue sections by calculating the percentage of total epithelial cells 
that stained positive, and mucin staining determined using a user-defined NIH ImageJ macro to calculate red channel density per 100 cells after image inversion. Because Alcian Blue can also stain basal lamina matrix proteins, staining at the basal lamina was not considered positive. Evaluation of mucus production using Periodic-Acid Schiff (PAS) staining was performed by scoring sections on a scale of $1-5$, based on extent of staining of epithelial layer and bronchiole lumen indicative of mucus plugs as described (Ledford et al., 2016). In these samples, a score of 1 represented diffuse mucus staining in the epithelial layer; a score of $2-3$ indicated increased mucus staining in the epithelial layer; a score of 4 reflected complete epithelial staining and additional mucus staining in the lumen; a score of 5 reflected complete lumen staining of mucus and full mucus plug of large lumens or multiple smaller lumens as described previously. A minimum of three sections were evaluated per mouse and reported scores reflect evaluation by at least 4 blinded evaluators.

To determine inflammatory cell counts, bronchoalveolar lavage fluid (BALF; $200 \mu \mathrm{l}$ ) was spun onto glass slides using a Shandon Cytospin and cells stained using Hema 3 stain kit (Fisher Scientific, \#22122911) following the manufacturer protocol. Differential counts were obtained by counting 200 cells per slide and categorized based on morphological criteria.

Data analysis: Sample sizes, $\mathrm{n}$, for all experiments reflect the number of independent values (either replicates for cell assays or individual mice). All statistical analyses were evaluated with GraphPad Prism software (San Diego, CA) on independent values. Multivariate comparisons were done with a two-way ANOVA with Tukey's multiple comparison post-test for individual experiments where the F-statistic exceeded the threshold for statistical significance. Pair-wise comparisons were conducted with a two-tailed Student'st -test. A value of $\mathrm{p}<0.05$ was used to establish a significant difference between samples. Data in Figures are graphed \pm Standard Error of the Mean (SEM) unless otherwise noted. This manuscript complies with the recommendations and requirements on experimental design and analysis set forth by the British Journal of Pharmacology (Curtis et al., 2018).

\section{RESULTS}

\section{C391 inhibits Alternaria alternata-induced signaling in airway epithelial and HEK293 cells}

Proteinases contained in A. alternata activate PAR2 to promote $\mathrm{Ca}^{2+}$ mobilization, $\beta$-arrestin recruitment and activation of downstream signaling events (Boitano et al., 2011; Yee et al., 2018). We have shown that $A$. alternata -induced $\mathrm{Ca}^{2+}$ mobilization in human airway epithelial (16HBE14o-) cells requires PAR2 (Boitano et al., 2011). To determine whether C391, which can block both peptidomimetic-induced and trypsin-induced PAR2 signaling (Boitano et al., 2015), can effectively block $A$. alternata -induced signals, we examined $\mathrm{Ca}^{2+}$ mobilization, MAPK phosphorylation and $\beta$-arrestin-2 recruitment. Treatment of 16HBE14o- cells with $A$. alternata $\left(\sim 0.65 \mathrm{U} / \mathrm{mL}\right.$ trypsin activity) raised $\left[\mathrm{Ca}^{2+}\right]_{\mathrm{i}}$ from an average resting concentration of $\sim 35 \mathrm{nM}$ to [?] $150 \mathrm{nM}$, within the 3 min experimental protocol, with $59.0 \pm 24.0 \%$ of cells showing a $\mathrm{Ca}^{2+}$ response $\left(\left[\mathrm{Ca}^{2+}\right]_{\mathrm{i}}>100 \mathrm{nM}\right)($ Figure 1A $, \mathbf{C}, \mathbf{E}-\mathbf{H} ; \mathrm{n}=3)$. Pre-incubation of cells with $3 \mu \mathrm{M}$ C391 for 2 min prior to addition of $A$. alternata significantly reduced the percentage of cells exhibiting a $\mathrm{Ca}^{2+}(6.4 \pm 2.7 \%)$, similar to that observed with $3 \mu \mathrm{M}$ C391 alone $(4.2 \pm 1.3 \%)$, and resulted in an average $\left[\mathrm{Ca}^{2+}\right]_{\mathrm{i}}$ of less than $75 \mathrm{nM}$ (Figure 1A, D, I-L ; n $=3, \mathrm{p}<0.05)$.

A. alternata has been shown to increase $\mathrm{Ca}^{2+}$ signaling, independent of PAR2, via ATP (O'Grady, Patil, Melkamu, Maniak, Lancto \& Kita, 2013). We thus repeated the C391 experiments following exposure of 16HBE14o- cells to either $1 \mu \mathrm{M}$ (data not shown) or $2.5 \mu \mathrm{M}$ ATP (Figure $\mathbf{1 M}-\mathbf{O}, \mathbf{n}=\mathbf{3}$ ), which induced a $\mathrm{Ca}^{2+}$ response in $15.2 \pm 3.8 \%$ and $62.3 \pm 11.5 \%$ of cells, respectively. This $\mathrm{Ca}^{2+}$ response was unaffected by pre-treatment with $3 \mu \mathrm{M}$ C391 which resulted in a response in $21.3 \pm 96.8 \%$ (1 $\mu \mathrm{M}$ ATP) and $53.8 \pm 9.4 \%$ $(2.5 \mu \mathrm{M}$ ATP) of cells. Due to the inherent similarities of PAR2 with other PARs, we also tested the effects of C391 on thrombin-induced $\mathrm{Ca}^{2+}$ signaling in 16HBE14o- cells (Figure 1M, P-Q ). High concentrations of thrombin $(100 \mu \mathrm{M})$ induced a low level of $\mathrm{Ca}^{2+}$ response in 16HBE14o- cells $(13.3 \pm 2.7 \%$; $\mathrm{n}=6)$ that was not statistically different when cells were pre-incubated with $3 \mu \mathrm{M}$ C391 $(11.0 \pm 3.6 \% ; \mathrm{n}=7)$.

Activation of PAR2 results in MAPK signalling, in part through a $\beta$-arrestin-dependent pathway, that can be measured via phosphorylation of the $42 \mathrm{kD}$ and $44 \mathrm{kD}$ MAPK family members (p-MAPK) and we 
have demonstrated previously that C391 inhibits peptidomimetic-induced MAPK activation (Boitano et al., 2015). Treatment of 16HBE14o- cells with increasing concentrations of A. alternata for 5 minutes resulted in a 1.4-fold increase in MAPK phosphorylation, with an $\mathrm{EC}_{50}$ of $35 \mu \mathrm{g} / \mathrm{mL}$ (Figure $2 \mathrm{~A} ; \mathrm{n}=4$ for all concentrations), similar to that observed with the peptidomimetic agonist 2-at-LIGRL- $\mathrm{NH}_{2}$ (600 nM; Figure 2B $; \mathrm{n}=4$ for all concentrations). However, a $95 \%$ confidence interval for pMAPK could not be constructed with A. alternata due to non-proteinase activation of MAPK pathways (O'Grady, Patil, Melkamu, Maniak, Lancto \& Kita, 2013; Yee et al., 2018). Pre-treatment with increasing concentrations of C391 (30 nM - 100 $\mu \mathrm{M})$ for $15 \mathrm{~min}$ inhibited $A$. alternata $(20 \mu \mathrm{g} / \mathrm{mL})$-induced p-MAPK with an $\mathrm{IC}_{50}$ of $12.6 \mu \mathrm{M}$ (CI: 3.2 $50.6 \mu \mathrm{M})$. C391 alone did not alter p-MAPK at any of the concentrations tested (not shown;Figure 2C ).

We have previously shown that $A$. alternata -induced activation of PAR2 leads to recruitment of $\beta$-arrestin-2, and many of the indicators of allergic asthma involving PAR2 activation are abolished in $\beta$-arrestin- $2^{-/-}$mice (Nichols et al., 2012; Yee et al., 2018). To determine whether C391 inhibits $\beta$-arrestin-2 recruitment to PAR-2 in response to $A$. alternata, we used bioluminescence resonance energy transfer (BRET) between PAR2-YFP and $\beta$-arrestin2-RLuc. We have previously used this technique to monitor recruitment of $\beta$-arrestin- 1 and 2 to PAR2 in response to trypsin, the potent peptidomimetic agonist 2-f-LIGRLO- $\mathrm{NH}_{2}$ (which is an equivalent agonist to 2-at-LIGRL- $\mathrm{NH}_{2}$ used in the $\mathrm{Ca}^{2+}$ and MAPK signaling assays), and A.alternata (Flynn et al., 2011; McGuire, Saifeddine, Triggle, Sun \& Hollenberg, 2004; Nichols et al., 2012; Yee et al., 2018). C391 blocked $\beta$-arrestin-2 recruitment in response to 2 -f-LIGRLO-NH ${ }_{2}\left(\operatorname{Imax}=88 \pm 4 \%\right.$; Log $\mathrm{IC}_{50}=-7.8 \pm 0.07$, CI: $7-21 \mathrm{nM}, \mathrm{n}=6$; Figure 3A $)$, or A. alternata $\left(\operatorname{Imax}=88 \pm 5 \% ; \log \mathrm{IC}_{50}=-7.9 \pm 0.17\right.$, CI $1-27 \mathrm{nM}$; $\mathrm{n}=3$; Figure 3B). We conclude that $\mathrm{C} 391$ can inhibit $A$. alternata -induced $\mathrm{Ca}^{2+}$ mobilization, MAPK phosphorylation and $\beta$-arrestin-2 recruitment, with similar efficacy to that seen when PAR2 is activated by peptidomimetic agonists or trypsin.

\section{Alternaria alternata-induced inflammation and mucus overproduction in $\mathrm{C} 57 \mathrm{Bl} / 6$ and $B A L B / c$ mice is limited by C391}

We have reported that intranasal administration A. alternataincreased PAR2-dependent inflammation, mucus production and mucus cell hyperplasia in wild type but not $\beta$-arrestin- $2^{-/-} \mathrm{C} 57 \mathrm{Bl} / 6$ mice (Yee et al., 2018). To determine if A. alternata-induced inflammation could be controlled pharmacologically with C391, we examined hallmarks of cellular inflammation after the same exposure to $8 \mu \mathrm{g} A$. alternata filtrate ( 3 times over 8 days), with or without C391. As previously reported, histological grading of Hematoxylin and Eosin (H \& E) -stained lungs (Figure $\mathbf{4 A - F} ; \mathbf{K}-\mathbf{L}, \mathbf{n}=\mathbf{3}$ ), revealed that A. alternata sensitization and challenge increased inflammation (histological score $3.3 \pm 0.2$ compared to $1.3 \pm 0.3$ in HBSS-treated controls) and epithelial thickening ( $2.4 \pm 0.28$-fold over saline controls). Concurrent administration of 2.5 nmoles C391 with $A$. alternata significantly reduced inflammation and epithelial thickening (histological scores of $1.2 \pm$ $0.1, \mathrm{p}<001$ and $0.98 \pm 0.0 .9, \mathrm{p}=.0012$, respectively). A lower dose (0.25 nmoles) of C391 reduced inflammation to a lesser extent (histological score of $2.3 \pm 0.25$ ) but did not significantly reduce epithelial thickening. A second hallmark of asthma is the increased production of mucus and A. alternata filtrate increased the number of epithelial cells staining positive for mucus ( $80.2 \pm 3.1 \%$ compared to $13.7 \pm 4.2 \%$ in saline controls), which was reduced by administration of C391 (42.8 $\pm 6.4 \%$ with $0.25 \mathrm{nM}$ and $33.9 \pm 2.3 \%$ with 2.5 nM C391, p<.001 for both concentrations; Figure 4G - J, M, n =3).

While the $\mathrm{C} 57 \mathrm{Bl} / 6$ mice from above provided comparison to studies that used genetically manipulated mice (Nichols et al., 2012; Yee et al., 2018), BALB/c mice represent a strain that is more prone to allergen response. $\mathrm{H} \& \mathrm{E}$ stains demonstrated extensive lung inflammation in response to A. alternata in BALB/c mice (Figure 5B ) that was reduced in the presence of C391 (Figure 5C ). A. alternata histology scores showed increased inflammation over control that was significantly reduced when the PAR2 antagonist C391 was included in the A. alternata filtrate (Figure $5 \mathrm{D} ; \mathrm{n}=4, \mathrm{p}<0.05$ ). Mucus staining and mucus cell hyperplasia in the BALB/c mice were evaluated via Periodic Acid Schiff (PAS) staining (Figure 5E - G ). $A$. alternata treatments significantly increased PAS staining from a limited baseline scoring ( 0 on a scale of 5 ; see Methods) to a robust mucus score $(4.2 \pm 0.2 ;$ Figure $\mathbf{5 F})$. Inclusion of C391 in the A. alternatatreatment significantly reduced the PAS score $(2.6 \pm 0.4, \mathrm{p}<0.05$; Figure 5G $)$, although this remained significantly 
above control scores (Figure 5E, $\mathbf{H}, \mathrm{p}<0.05)$.

\section{Cellular composition of Alternaria-induced airway inflammation}

A. alternata increased the total number of cells in BALF in both $\mathrm{C} 57 \mathrm{Bl} / 6$ mice (Figure $\mathbf{6 A}, \mathbf{B} ; \mathrm{n}=3$ mice per group) and BALB/c mice (Figure 6C, $\mathbf{D} ; \mathrm{n}=4$ mice per group). Differential cell counts demonstrated that the primary inflammation was due to increased eosinophils (increasing from 1,150 \pm 450 cells to 18,000 \pm 4,700 cells in C57/Bl-6 and from $240 \pm 140$ cells to 49,000 $\pm 15,000$ cells in BALB/c), and lymphocytes (increasing from $2400 \pm 821$ to $16,000 \pm 2656$ cells in $\mathrm{C} 57 \mathrm{Bl} / 6$ and $650 \pm 550$ to $12,000 \pm 3,000$ cells in BALB/c). In C57Bl/6 mice, $2.5 \mathrm{nM}$ C391 reduced eosinophils and lymphocytes in the BALF by $90 \%$ $(2100 \pm 750,1700 \pm 500)$. Treatment with a lower concentration of C391 (0.25 nmoles) reduced eosinophils by $75 \%(4300 \pm 1900)$ and lymphocytes by $80 \%(3300 \pm 550)$. In BALB/c mice, treatment with $5 \mathrm{nM}$ C391 reduced eosinophils in the BALF $50 \%$ (23,000 \pm 756 cells) and lymphocytes by $80 \%(2,700 \pm 476$ cells), but only the reduction in lymphocytes was statistically significant $(\mathrm{p}<0.05)$ compared to the A. alternata treatment. In BALB/c but not C57Bl/6 mice, A. alternata significantly increased the number of macrophages in the BALF (38,000 \pm 610 cells to $95,000 \pm 1,400$ cells, respectively) and this was significantly reduced by C391 (48,000 $\pm 6,200$ cells, $\mathrm{p}<0.05)$. A minimal neutrophilic response was observed in both mouse strains and this was not reduced by C391. Taken together, these data support that A. alternata -mediated airway inflammation (infiltration of eosinophils and lymphocytes, epithelial thickening, and mucus overproduction) in $\mathrm{C} 57 \mathrm{Bl} / 6$ and $\mathrm{BALB} / \mathrm{c}$ mice, can be inhibited by the PAR2 antagonist, C391.

\section{Alternaria alternata-induced airway hyperresponsiveness in $B A L B / c$ mice}

To better evaluate the physiological response of mice to A. alternata and the potential for C391 to limit this response, we used the forced oscillation technique to measure respiratory resistance in response to methacholine (MCh) challenge in A. alternata -sensitized/challenged BALB/c mice (Addison, Morse, Robichaud, Daines \& Ledford, 2017). A. alternata treatment resulted in an increase in airway hyperresponsiveness (AHR) to MCh as reported by total airway resistance (Max Rrs \% over baseline) that intensified with each dose of MCh. In comparison, mice treated with HBSS alone responded to MCh challenges with stable and relatively low total airway resistance(Figure 7) . In contrast to A. alternata- treated mice, mice receiving both A. alternata and C391 exhibited significantly reduced total airway resistances that were not significantly different than total airway resistances observed in HBSS-treated control animals. These results suggest PAR2 inhibition by C391 is effective at protecting against the development of AHR in an acute, A. alternata -sensitized/challenged murine model.

\section{DISCUSSION}

In this study we demonstrate that the potent PAR2 antagonist, C391, can effectively inhibit allergen $(A l-$ ternaria alternata )-induced canonical PAR2 signaling $\left(\mathrm{Ca}^{2+}\right.$ and $\beta$-arrestin/MAPK) in human cell lines and significantly diminish $A$. alternata -induced asthma indicators in pre-clinical murine models. Immortalized human bronchial epithelial cells, such as 16HBE14o-, are widely used in pharmacological in vitro studies centered around pulmonary physiology (Forbes, Shah, Martin \& Lansley, 2003). They are ideal for drug discovery in the space of PAR-2-directed asthma therapeutics because they naturally express PAR2 and retain many features of differentiated bronchial epithelial cells including tight junction formation, barrier function and directional ion transport (Cozens et al., 1994). C391 was the first PAR-2 antagonist we identified, using 16HBE14o- for initial screening and subsequent assessment of $\mathrm{Ca}^{2+}$ and MAPK activation in response to trypsin and high-affinity peptidomimetic PAR2 agonists (Boitano et al., 2015; Flynn et al., 2011). Here, we have expanded the in vitro analyses of C391 to verify that it can effectively inhibit natural asthma-associated allergen (A. alternata )-induced, PAR2-dependent $\mathrm{Ca}^{2+}$ and MAPK activation in airway epithelial cells. Since PAR-2 can promote MAPK activation through both G-protein and $\beta$-arrestin pathways (Ge, Ly, Hollenberg \& DeFea, 2003), and $\beta$-arrestin-dependent signaling is crucial for the inflammatory effects of $A$. alternata -induced PAR2 activation in the airway (Nichols et al., 2012; Yee et al., 2018), we have also confirmed that C391 inhibits $\beta$-arrestin recruitment, using BRET in transfected HEK293 cells.

We show that this PAR2 antagonist effectively reduces asthma indicators (including inflammation, eosinophil 
infiltration, mucus cell hyperplasia/mucus overproduction and airway hyperresponsiveness) in twoAlternaria alternata -induced murine asthma models. Asthma-associated allergen exposure in mouse models normally triggers a cascade of Th2 cytokine producing processes that result in eosinophil and leukocyte recruitment and residence in the airway (Wardlaw, 1999). While we cannot conclude as to where in the inflammatory pathway C391 is altering recruitment (e.g., airway epithelial- or other cell-dependent cytokine/chemokine release, or in the inflammatory cell response to increased proteinase), it is clear that concurrent or prophylactic treatment of C391 is effective in limiting A. alternata -induced inflammatory cell recruitment, mucus overproduction and airway hyperresponsiveness. More work is needed to clarify if C391 antagonism of A. alternata-induced signaling is sufficient to reduce asthma indicators (i.e., act as a therapeutic) or, if C391 is additionally antagonizing downstream, endogenous protease activation of PAR2 on epithelial cells or other cells in the airway.

Serine proteinases that activate PAR2 are a recurring theme among asthma-associated allergens (Adams et al., 2011), including those fromAlternaria and other molds (Boitano et al., 2011; Chiu, Perng, Yu, Su \& Chow, 2007; Yee et al., 2018), house dust mite (Stewart, Thompson \& Simpson, 1989; Sun, Stacey, Schmidt, Mori \& Mattoli, 2001) and cockroach (Ock, Kim, Kim \& Byun, 2005; Polley et al., 2017; Sudha, Arora, Gaur, Pasha \& Singh, 2008). PAR2 ${ }^{-/}$murine models have been used to demonstrate a key role for PAR2 in the inflammation induced by these allergens (Davidson et al., 2013; Day, Zhou, Ledford \& Page, 2010; Page, Ledford, Zhou, Dienger \& Wills-Karp, 2010; Yee et al., 2018). Additionally, mast cell tryptase and neutrophil elastase represent endogenous PAR2-activating proteases that contribute to the asthma phenotype (Andersson, Tufvesson, Diamant \& Bjermer, 2016; Kabashima et al., 2018; Ogawa et al., 2018). PAR2-neutralizing antibodies were recently shown to reduce asthma symptoms in acute and chronic allergic asthma mouse models (Asaduzzaman, Davidson, Nahirney, Fiteih, Puttagunta \& Vliagoftis, 2018; Asaduzzaman et al., 2015), and over-expression of PAR2 or intranasal administration of PAR-2 activating peptides (SLIGRL or 2-furoyl-LIGRLO-NH${ }_{2}$ ) promotes cellular inflammation and airway hyperresponsiveness(Ebeling, Forsythe, Ng, Gordon, Hollenberg \& Vliagoftis, 2005; Nichols et al., 2012). Paradoxically, PAR2 activation also results in a beneficial $\mathrm{Ca}^{2+}$-dependent $\mathrm{PGE}_{2}$ secretion from airway epithelial cells, allowing for smooth muscle relaxation (Chow, Moffatt \& Cocks, 2000; Cocks et al., 1999; Henry, 2006; Jairaman, Yamashita, Schleimer \& Prakriya, 2015; Nichols et al., 2012) and resolution of neutrophilia (Rayees et al., 2019). We have demonstrated that the protective and inflammatory responses are mediated by separate G-protein and $\beta$-arrestin-2 signaling pathways, respectively (Nichols et al., 2012; Yee et al., 2018). While these studies might suggest that a biased antagonist that effectively prevents PAR2-dependent $\beta$-arrestin signaling, C391 mitigates multiple asthma indicators, including airway hyperresponsiveness, despite blocking both pathways.

There are only a handful of PAR2 antagonists that have been developed [reviewed in (Yau, Lim, Liu \& Fairlie, 2016)]. These include K-14585 (Goh, Ng, Nilsson, Kanke \& Plevin, 2009; Kanke et al., 2005), GB88 (Hollenberg et al., 2014; Suen et al., 2012; Suen et al., 2014), two small molecules isolated from a large screening library (AC-55541 and AC-264613; (Gardell et al., 2008)), two PAR2 allosteric antagonists AZ8838 and AZ3451 from Astra Zeneca (Cheng et al., 2017; Kennedy et al., 2020), a group of small molecules: I-343, I-191 and I-287, from Vertex (Avet et al., 2020; Jiang et al., 2018; Jimenez-Vargas et al., 2018), and C391 (Boitano et al., 2015). C391 is distinct from these other antagonists in that it requires minimal pre-incubation for inhibition of multiple PAR2 signaling pathways. Although we observed differences in calculated $\mathrm{IC}_{50}$ values for $\mathrm{C} 391$ between the in vitro $\mathrm{Ca}^{2+}$ and MAPK signaling $(\mu \mathrm{M})$ and $\beta$-arrestin recruitment $(\mathrm{nM})$, these experiments were in different cell types that include naturally expressed PAR2 (16HBE14o- cells used for $\mathrm{Ca}^{2+}$ and MAPK) vs transfected PAR2 (HEK 293 cells for $\beta$-arrestin), and we cannot conclude that C391 is a biased antagonist. Other small molecule PAR2 antagonists also show differences in potency for different signaling pathways. For example, AZ3451 was reported to have a lower $\mathrm{IC}_{50}$ for $\mathrm{Ca}^{2+}$ mobilization $(\mathrm{nM})$ than for $\beta$-arrestin-2 recruitment $(\mu \mathrm{M})$ and AZ8588 was reported to have a lower $\mathrm{IC}_{50}$ for $\beta$-arrestin-2 recruitment than $\mathrm{Ca}^{2+}$ mobilization. Both compounds inhibited inflammation to a similar extent in a paw edema model (Kennedy et al., 2020). The PAR2 antagonists from Vertex all inhibited PAR2-induced Gprotein but not $\beta$-arrestin signaling and show partial efficacy in mouse models of pain and subcutaneous inflammation (Avet et al., 2020; Jiang et al., 2018; Jimenez-Vargas et al., 2018). While these inhibitors show 
efficacy in peripheral inflammation and pain models, the ability to inhibit $\beta$-arrestin signaling appears to be important for reduction of asthma indicators, making C391 a more promising therapeutic. It is possible C391 could be further modified to be more selective for $\beta$-arrestin- 2 and this might increase its efficacy as an asthma therapeutic.

Asthma can be triggered by environmental allergens such as Alternaria, pollens, insect droppings and infection. Due to the heterogeneity of its pathology, it remains difficult to manage in some patients, particularly those with moderate to severe disease. Many of the commonly used treatments for asthma address symptoms without addressing underlying triggers for the disease. Traditional treatments include corticosteroids and mast cell stabilizers for inflammation control, short and long acting $\beta_{2}$-agonists to relax bronchial smooth muscle and increase airflow; anticholinergics as supplemental broncho-relaxants and, leukotriene disruptors (receptor antagonists or leukotriene synthesis inhibitors) used as an anti-inflammatory therapy (Martinez \& Vercelli, 2013; Pera \& Penn, 2016). Monoclonal antibody treatments that target immunoglobulin E, IL-13, IL-5 or IL-4-Receptor show some potential for patients with moderate to severe asthma who remain poorly controlled with steroids, although clinical trials have had mixed results. Some patients experienced improved lung function; however, in many cases overall eosinophilic inflammation was not significantly reduced and clinical endpoint reduction was limited (Chung, 2018; Hanania et al., 2016; Stephenson et al., 2016). Despite these varied approaches, asthma remains uncontrolled in more than half the patients receiving standard asthma medication (Peters, Jones, Haselkorn, Mink, Valacer \& Weiss, 2007). While a portion of this population includes non-compliant patients, a large proportion of patients with refractory asthma would stand to benefit from improved therapeutics that ameliorate allergic asthma symptoms. Given that PAR2 is upregulated in both human respiratory epithelium and peripheral blood monocytes in asthmatics (Knight et al., 2001; Shrestha Palikhe et al., 2015), PAR2 signaling is of great interest in asthma development and severity.

A primary advance in this work is the first demonstration of pharmacological inhibition of allergen-induced asthma indicators (inflammation, mucus secretion and airway hyperresponsiveness) in pre-clinical animal models. That C391 reduces airway mucus production is also particularly exciting because of its potential for reducing asthma mortality. It has been observed that airway mucus plugging due to goblet cell hyperplasia coupled with peripheral airway mucus accumulation appears to be more prevalent in patients who eventually succumb to a severe asthma attack (Aikawa, Shimura, Sasaki, Ebina \& Takishima, 1992). These same patients appear to be hypo-responsive to bronchodilators and anti-inflammatory medications. Providing a therapy that could control mucus production would allow for control of disease through minimizing airway obstruction caused by mucus plugging and possibly provide improved patient outcomes. C391 also reduced the development of airway hyperresponsiveness (AHR) in our pre-clinical models. AHR closely resembles a bronchoconstriction event or asthma attack in sensitized individuals and represents a measure that is commonly used in diagnostic procedures in the clinic. This suggests inhibition of PAR2 would be useful for prophylaxis in vulnerable individuals and as a potential treatment for airway hyperresponsiveness in allergic asthmatics.

We acknowledge that the studies here represent a prophylactic treatment and it is unknown if application of PAR2 pharmacophores could be effective in a therapeutic setting, e.g., after the establishment of asthma. However, these data, and the recent report that PAR2-specific antibodies can be effective in both preventing and controlling asthma indicators in pre-clinical exposure models (Asaduzzaman, Davidson, Nahirney, Fiteih, Puttagunta \& Vliagoftis, 2018; Davidson et al., 2013) support PAR2 as a druggable target for addressing allergen-induced asthma. Furthermore, C391 specifically presents as a novel lead compound in the pursuit of novel asthma drugs.

\section{Figure Legends}

Figure 1: A. alternata -induced $\mathrm{Ca}^{2+}$ signaling in airway epithelial cells is blocked by C391. (A)Percentage of $16 \mathrm{HBE} 14 \mathrm{o}-$ cells responding with $\left[\mathrm{Ca}^{2+}\right]_{\mathrm{i}}$ increases [?] $150 \mathrm{nM}$ within the experimental time frame following A. alternata ( \pm C391) addition. (B - D) Representative population graphs from single experiments depicting the average change in $\left[\mathrm{Ca}^{2+}\right]_{\mathrm{i}}$ in $16 \mathrm{HBE} 14 \mathrm{o}-$ cells in response to indicated compound plotted over time and shown with SEM in the presence of: (B) $3 \mu \mathrm{M}$ C391 alone; (C) A. alternata $\mathrm{EC}_{50}$ 
alone and (D)EC $\mathrm{E}_{50}$ of $A$. alternata combined with $3 \mu \mathrm{M}$ C391.(E - H) Changes in $\left[\mathrm{Ca}^{2+}\right]_{\mathrm{i}}$ are shown as color maps over time in response to A. alternata filtrate. Individual panels are from (E) 20 sec prior to $\mathrm{EC}_{50}$ of $A$. alternata filtrate addition and at $(\mathbf{F}-\mathbf{H}) 60 \mathrm{sec}$ intervals. White lines approximate cell borders, color key for $\left[\mathrm{Ca}^{2+}\right]_{\mathrm{i}}$ is displayed in lower right of first panel. (I - L) The same experiment as $(\mathbf{E}-\mathbf{H})$ excepting a 2 min preincubation with $3 \mu \mathrm{M}$ C391 and continued $3 \mu \mathrm{M}$ C391 treatment during A. alternata filtrate exposure.(M) Percentage of $16 \mathrm{HBE} 14 \mathrm{o}-$ cells responding with $\left[\mathrm{Ca}^{2+}\right]_{\mathrm{i}}$ increases [?] $150 \mathrm{nM}$ within the experimental time frame in response to the P2Y agonist ATP $(2.5 \mu \mathrm{M})$ or the PAR1 agonist Thrombin $(100 \mu \mathrm{M}) \pm$ C391. (N-Q)Representative population graphs from single experiments depicting the average change in $\left[\mathrm{Ca}^{2+}\right]_{\mathrm{i}}$ in 16HBE14o- cells in response to indicated compound plotted over time and shown with SEM in the presence of: (N) $2.5 \mu \mathrm{M}$ ATP alone;(O) $2.5 \mu \mathrm{M}$ ATP and $3 \mu \mathrm{M}$ C391 (P) $100 \mu \mathrm{M}$ Thrombin;(Q) $100 \mu \mathrm{M}$ Thrombin and $3 \mu \mathrm{M}$ C391.

Figure 2: A. alternata -induced MAPK signaling in airway epithelial cells is inhibited by C391. (A) MAPK phosphorylation (p-MAPK) undergoes a concentration-dependent increase in response to the potent and selective PAR2 agonist 2at-LIGRL- $\mathrm{NH}_{2}$. (B) MAPK phosphorylation (p-MAPK) undergoes a concentration-dependent increase in response to $A$. alternata filtrates. (C) Concentration response curve for C391 block of $A$. alternata $(20 \mu \mathrm{g} / \mathrm{mL})$-induced MAPK phosphorylation; $\mathrm{IC}_{50}$ is noted in the text. For all experiments, 3 [?] n [?] 4. * indicates difference from HBSS-treated control(A, B) or from A. alternata -treated control(C), p [?] 0.05 .

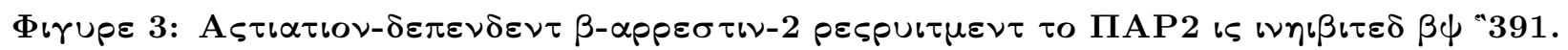
Bioluminescence resonance energy transfer (BRET) was measured upon addition of: (A) the potent PAR2 agonist 2-furoyl-LIGRLO- $\mathrm{NH}_{2}(1 \mu \mathrm{M})$ or $($ B) A alternata filtrate $($ Alt $; 65 \mu \mathrm{g} / \mathrm{mL})$ and increasing concentrations of C391. C391 effectively blocked $\beta$-arrestin- 2 recruitment following PAR2 activation via peptidomimetic or A. alternata proteinase. $\mathrm{n}$ [?] 3 for all experimental time points; $\mathrm{IC}_{50}$ s are noted in the text.

Figure 4: C391 reduces asthma indicators in a C57Bl/6 murine model. (A - F) Typical H\&E staining of C57Bl/6 lungs treated with: (A) HBSS; (B, E) A. alternata ;(C) A. alternata +0.25 nmoles C391 or $(\mathbf{D}, \mathbf{F})$ A. alternata +2.5 nmoles C391. Images A-D were imaged with 10X and E-F were imaged with a $40 \mathrm{X}$ objective. A. alternata induces significant inflammation (increased cellular staining) that is reduced by low concentrations of C391 and mostly eliminated by higher concentrations of C391. (G - J) Typical Alcian Blue staining of $\mathrm{C} 57 \mathrm{Bl} / 6$ lungs treated with: (G) HBSS vehicle control;(H) A alternata ; (I) A. alternata +0.25 nmoles C391 or (J) A. alternata +2.5 nmoles C391.(K - L) Semi-quantitative histological grading of lung inflammation and Alcian Blue staining shows a significant increase in cellular infiltrate $(\mathbf{K})$, thickening of the basement membrane (L ) \% bronchial epithelial cells displaying positive mucus staining (M ), that are significantly reduced by either low (0.25 nmoles) or high (2.5 nmoles) C391 concentrations. $\mathrm{n}=3$ for all experiments, ${ }^{*}$ indicates significant difference from HBSS control, \# indicates significant difference from $A$. alternata -induced changes; $\mathrm{p}$ [?] 0.05 .

Figure 5: C391 reduces asthma indicators in BALB/c murine model. (A - D) Typical H\&E staining of BALB/c lung slices from animals treated with: (A) HBSS vehicle control;(B) A. alternata ; or (C) A. alternata +5 nmoles C391. (D) Semi-quantification of H\&E staining. Typical PAS staining of BALB/c lung slices from animals treated with:(E) HBSS vehicle control; (F) A. alternata ; $(\mathbf{G})$ or A. alternata +5 nmoles C391. (H)Semi-quantification of PAS staining. A. alternata treatment induces significant increases in inflammation and mucus production that is reduced by C391. B denotes bronchioles, M denotes mucus plug, simple arrows indicate inflammatory cell staining and closed arrows are directed at goblet cell staining. $\mathrm{n}$ [?] 4 for all experiments; * indicates significant difference from HBSS control; \# indicates significant difference from A. alternata -induced staining; p [?] 0.05.

Figure 6: C391 Reduces airway leukocyte recruitment in C57Bl/6 and BALB/c murine asthma models.

(A - D) Quantification of bronchoalveolar lavage fluid (BALF) cell counts in C57Bl/6 (A,B) and BALB/c 
(C, D ) as follows: (A, C ) total cells; (B, D) neutrophils, eosinophils, lymphocytes, and macrophages (with macrophage quantification shown on the right $\mathrm{y}$ - axis). A. alternatatreatment significantly increased total cell infiltration, and specifically the recruitment of eosinophils and lymphocytes in both mouse strains, as well as increased macrophages in BALB/c. Eosinophils and lymphocytes in C57Bl/6 were significantly attenuated in A. alternata exposed mice treated with C391, and lymphocytes and macrophages were significantly attenuated in $A$. alternata exposed mice treated with $\mathrm{C} 391$ in BALB/c. * Indicates significant difference between HBSS treated and $A$. alternata exposed mice; p [?] 0.05 . \# Indicates significant difference between A. alternata exposed mice and A. alternata exposed mice treated with C391; p [?] 0.05 .

Figure 7: C391 reduces airway hyperresponsiveness in a BALB/c murine asthma model.

BALB/c mice were given nasal instillations of treatment (HBSS control,A. alternata or A. alternata with C391) on days $0,3,6$ and forced oscillation technique with methacholine challenge to measure lung resistance was performed on day 8. The percent change in maximum total airway resistance (Max Rrs) is reported. A. alternata treatment increases Max Rrs measurements over control. However, A. alternata treatment in the presence of C391 the Max Rrs are similar to control. n [?] 4 for each treatment. * Indicates significant difference between HBSS treated and A. alternataexposed mice; $\mathrm{p}$ [?] 0.05. \# Indicates significant difference between A. alternata exposed mice and A. alterna ta exposed mice treated with C391; p [?] 0.05.

\section{References}

Adam E, Hansen KK, Astudillo Fernandez O, Coulon L, Bex F, Duhant X, et al. (2006). The house dust mite allergen Der p 1, unlike Der p 3, stimulates the expression of interleukin-8 in human airway epithelial cells via a proteinase-activated receptor-2-independent mechanism. J Biol Chem 281: 6910-6923.

Adams MN, Ramachandran R, Yau MK, Suen JY, Fairlie DP, Hollenberg MD, et al. (2011). Structure, function and pathophysiology of protease activated receptors. Pharmacol Ther 130: 248-282.

Addison KJ, Morse J, Robichaud A, Daines MO, \& Ledford JG (2017). A Novel in vivo System to Test Bronchodilators. J Infect Pulm Dis 3.

Aikawa T, Shimura S, Sasaki H, Ebina M, \& Takishima T (1992). Marked goblet cell hyperplasia with mucus accumulation in the airways of patients who died of severe acute asthma attack. Chest 101:916-921.

Andersson C, Tufvesson E, Diamant Z, \& Bjermer L (2016). Revisiting the role of the mast cell in asthma. Curr Opin Pulm Med 22: 10-17.

Arizmendi NG, Abel M, Mihara K, Davidson C, Polley D, Nadeem A, et al. (2011). Mucosal allergic sensitization to cockroach allergens is dependent on proteinase activity and proteinase-activated receptor-2 activation. J Immunol 186: 3164-3172.

Asaduzzaman M, Davidson C, Nahirney D, Fiteih Y, Puttagunta L, \& Vliagoftis H (2018). Proteinaseactivated receptor-2 blockade inhibits changes seen in a chronic murine asthma model. Allergy 73:416-420.

Asaduzzaman M, Nadeem A, Arizmendi N, Davidson C, Nichols HL, Abel M, et al. (2015). Functional inhibition of PAR2 alleviates allergen-induced airway hyperresponsiveness and inflammation. Clin Exp Allergy 45: 1844-1855.

Avet C, Sturino C, Grastilleur S, Gouill CL, Semache M, Gross F, et al. (2020). The PAR2 inhibitor I-287 selectively targets Galphaq and Galpha12/13 signaling and has anti-inflammatory effects. Commun Biol 3: 719.

Batra M, Vicendese D, Newbigin E, Lambert KA, Tang M, Abramson MJ, et al. (2021). The association between outdoor allergens - pollen, fungal spore season and high asthma admission days in children and adolescents. Int J Environ Health Res: 1-10.

Boitano S, Flynn AN, Sherwood CL, Schulz SM, Hoffman J, Gruzinova I, et al. (2011). Alternaria alternata serine proteases induce lung inflammation and airway epithelial cell activation via PAR2. Am J Physiol 
Lung Cell Mol Physiol 300: L605-614.

Boitano S, Hoffman J, Flynn AN, Asiedu MN, Tillu DV, Zhang Z, et al. (2015). The novel PAR2 ligand C391 blocks multiple PAR2 signaling pathways in vitro and in vivo. British journal of pharmacology 172 : 4535-4545.

Bush RK, \& Prochnau JJ (2004). Alternaria-induced asthma. J Allergy Clin Immunol 113: $227-234$.

Cheng RKY, Fiez-Vandal C, Schlenker O, Edman K, Aggeler B, Brown DG, et al. (2017). Structural insight into allosteric modulation of protease-activated receptor 2. Nature 545: 112-115.

Chiu LL, Perng DW, Yu CH, Su SN, \& Chow LP (2007). Mold allergen, pen C 13, induces IL-8 expression in human airway epithelial cells by activating protease-activated receptor 1 and 2. J Immunol 178:5237-5244.

Chow JM, Moffatt JD, \& Cocks TM (2000). Effect of protease-activated receptor (PAR)-1, -2 and -4activating peptides, thrombin and trypsin in rat isolated airways. Br J Pharmacol 131: 1584-1591.

Chung KF (2018). Tralokinumab unsuccessful for management of severe, uncontrolled asthma. Lancet Respir Med 6: 480-481.

Cocks TM, Fong B, Chow JM, Anderson GP, Frauman AG, Goldie RG, et al. (1999). A protective role for protease-activated receptors in the airways. Nature 398: 156-160.

Cozens AL, Yezzi MJ, Kunzelmann K, Ohrui T, Chin KE, Finkbeiner WE, et al. (1994). CFTR expression and chloride secretion in polarized immortal human bronchail epithelial cells. Am J Respir Cell Mol Biol 10: $38-47$.

Curtis MJ, Alexander S, Cirino G, Docherty JR, George CH, Giembycz MA, et al. (2018). Experimental design and analysis and their reporting II: updated and simplified guidance for authors and peer reviewers. Br J Pharmacol 175: 987-993.

Davidson CE, Asaduzzaman M, Arizmendi NG, Polley D, Wu Y, Gordon JR, et al. (2013). Proteinaseactivated receptor-2 activation participates in allergic sensitization to house dust mite allergens in a murine model. Clin Exp Allergy 43: 1274-1285.

Day SB, Zhou P, Ledford JR, \& Page K (2010). German cockroach frass proteases modulate the innate immune response via activation of protease-activated receptor-2. J Innate Immun 2: 495-504.

Ebeling C, Forsythe P, Ng J, Gordon JR, Hollenberg M, \& Vliagoftis H (2005). Proteinase-activated receptor 2 activation in the airways enhances antigen-mediated airway inflammation and airway hyperresponsiveness through different pathways. J Allergy Clin Immunol 115: 623-630.

Flynn AN, Tillu DV, Asiedu MN, Hoffman J, Vagner J, Price TJ, et al. (2011). The protease-activated

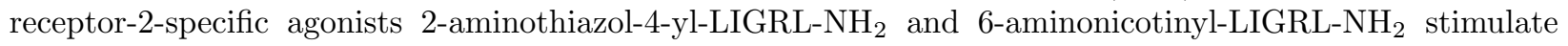
multiple signaling pathways to induce physiological responses in vitro and in vivo. The Journal of Biological Chemistry 286: 19076-19088.

Forbes B, Shah A, Martin GP, \& Lansley AB (2003). The human bronchial epithelial cell line 16HBE140as a model system of the airways for studying drug transport. Int J Pharm 257: 161-167.

Gardell LR, Ma JN, Seitzberg JG, Knapp AE, Schiffer HH, Tabatabaei A, et al. (2008). Identification and characterization of novel small-molecule protease-activated receptor 2 agonists. J Pharmacol Exp Ther 327: 799-808.

Ge L, Ly Y, Hollenberg M, \& DeFea K (2003). A \&\#x3b2;-Arrestin-dependent Scaffold Is Associated with Prolonged MAPK Activation in Pseudopodia during Protease-activated Receptor-2-induced Chemotaxis *. Journal of Biological Chemistry 278: 34418-34426.

Goh FG, Ng PY, Nilsson M, Kanke T, \& Plevin R (2009). Dual effect of the novel peptide antagonist K-14585 on proteinase-activated receptor-2-mediated signalling. British journal of pharmacology 158: 1695-1704. 
Gruenert DC, Finkbeiner WE, \& Widdicombe JH (1995). Culture and transformation of human airway epithelial cells. Am J Physiol 268: L347-360.

Grynkiewicz G, Poenie M, \& Tsien RY (1985). A new generation of $\mathrm{Ca}^{2+}$ indicators with greatly improved fluorescence properties. J Biol Chem 260: 3440-3450.

Halonen M, Stern DA, Wright AL, Taussig LM, \& Martinez FD (1997). Alternaria as a major allergen for asthma in children raised in a desert environment. Am J Respir Crit Care Med 155: 1356-1361.

Hanania NA, Korenblat P, Chapman KR, Bateman ED, Kopecky P, Paggiaro P, et al. (2016). Efficacy and safety of lebrikizumab in patients with uncontrolled asthma (LAVOLTA I and LAVOLTA II): replicate, phase 3, randomised, double-blind, placebo-controlled trials. Lancet Respir Med 4: 781-796.

Henry PJ (2006). The protease-activated receptor2 $\left(\mathrm{PAR}_{2}\right)$-prostaglandin E2-prostanoid EP receptor axis: a potential bronchoprotective unit in the respiratory tract? Eur J Pharmacol 533: 156-170.

Hoffman J, Flynn A, Tillu D, Zhang Z, Patek R, Price T, et al.(2012). Lanthanide labeling of a potent protease activated receptor-2 agonist for time-resolved fluorescence analysis. Bioconjug Chem 23: 20982104 .

Hollenberg MD, Mihara K, Polley D, Suen JY, Han A, Fairlie DP, et al. (2014). Biased signalling and proteinase-activated receptors (PARs): targeting inflammatory disease. British journal of pharmacology 171: $1180-1194$.

Hollenberg MD, Saifeddine M, \& al-Ani B (1996). Proteinase-activated receptor-2 in rat aorta: structural requirements for agonist activity of receptor-activating peptides. Mol Pharmacol 49: 229-233.

Huang X, Ni B, Xi Y, Chu X, Zhang R, \& You H (2019). Protease-activated receptor 2 (PAR-2) antagonist AZ3451 as a novel therapeutic agent for osteoarthritis. Aging (Albany NY) 11: 12532-12545.

Jairaman A, Yamashita M, Schleimer RP, \& Prakriya M (2015). Store-Operated Ca2+ Release-Activated $\mathrm{Ca} 2+$ Channels Regulate PAR2-Activated Ca2+ Signaling and Cytokine Production in Airway Epithelial Cells. J Immunol.

Jiang Y, Yau MK, Lim J, Wu KC, Xu W, Suen JY, et al. (2018). A Potent Antagonist of Protease-Activated Receptor 2 That Inhibits Multiple Signaling Functions in Human Cancer Cells. J Pharmacol Exp Ther 364: 246-257.

Jimenez-Vargas NN, Pattison LA, Zhao P, Lieu T, Latorre R, Jensen DD, et al. (2018). Protease-activated receptor-2 in endosomes signals persistent pain of irritable bowel syndrome. Proc Natl Acad Sci U S A.

Kabashima K, Nakashima C, Nonomura Y, Otsuka A, Cardamone C, Parente R, et al. (2018). Biomarkers for evaluation of mast cell and basophil activation. Immunol Rev 282: 114-120.

Kanke T, Ishiwata H, Kabeya M, Saka M, Doi T, Hattori Y, et al.(2005). Binding of a highly potent proteaseactivated receptor-2 (PAR2) activating peptide, [3H]2-furoyl-LIGRL-NH2, to human PAR2. British journal of pharmacology 145: 255-263.

Kennedy AJ, Sundström L, Geschwindner S, Poon EKY, Jiang Y, Chen R, et al. (2020). Protease-activated receptor-2 ligands reveal orthosteric and allosteric mechanisms of receptor inhibition. Communications Biology 3: 782 .

Knight DA, Lim S, Scaffidi AK, Roche N, Chung KF, Stewart GA, et al. (2001). Protease-activated receptors in human airways: upregulation of PAR-2 in respiratory epithelium from patients with asthma. J Allergy Clin Immunol 108: 797-803.

Ledford JG, Addison KJ, Francisco D, Foster MW, Voelker DR, Que LG, et al. (2016). Genetic Variation in Surfactant Protein-A2 Results in Altered Regulation of Eosinophil Activities and Enhanced Eosinophilia in Patients with Asthma. Ann Am Thorac Soc 13 Suppl 1: S101. 
Lombardi C, Savi E, Ridolo E, Passalacqua G, \& Canonica GW (2017). Is allergic sensitization relevant in severe asthma? Which allergens may be culprit? World Allergy Organ J 10: 2.

Martinez FD, \& Vercelli D (2013). Asthma. Lancet 382:1360-1372.

McGuire JJ, Saifeddine M, Triggle CR, Sun K, \& Hollenberg MD (2004). 2-furoyl-LIGRLO-amide: a potent and selective proteinase-activated receptor 2 agonist. J Pharmacol Exp Ther 309: 1124-1131.

Mendy A, Wilkerson J, Salo PM, Zeldin DC, \& Thorne PS (2020). Endotoxin clustering with allergens in house dust and asthma outcomes in a U.S. national study. Environ Health 19: 35.

Nichols HL, Saffeddine M, Theriot BS, Hegde A, Polley D, El-Mays T, et al. (2012). beta-Arrestin-2 mediates the proinflammatory effects of proteinase-activated receptor-2 in the airway. Proc Natl Acad Sci U S A 109: 16660-16665.

O'Grady SM, Patil N, Melkamu T, Maniak PJ, Lancto C, \& Kita H (2013). ATP release and Ca2+ signalling by human bronchial epithelial cells following Alternaria aeroallergen exposure. J Physiol 591:4595-4609.

Ock MS, Kim BJ, Kim SM, \& Byun KH (2005). Cloning and expression of trypsin-encoding cDNA from Blattella germanica and its possibility as an allergen. Korean J Parasitol 43: 101-110.

Ogawa H, Azuma M, Tsunematsu T, Morimoto Y, Kondo M, Tezuka T, et al. (2018). Neutrophils induce smooth muscle hyperplasia via neutrophil elastase-induced FGF-2 in a mouse model of asthma with mixed inflammation. Clin Exp Allergy 48: 1715-1725.

Page K, Ledford JR, Zhou P, Dienger K, \& Wills-Karp M (2010). Mucosal sensitization to German cockroach involves protease-activated receptor-2. Respir Res 11: 62.

Pera T, \& Penn RB (2016). Bronchoprotection and bronchorelaxation in asthma: New targets, and new ways to target the old ones. Pharmacol Ther 164: 82-96.

Peters SP, Jones CA, Haselkorn T, Mink DR, Valacer DJ, \& Weiss ST (2007). Real-world Evaluation of Asthma Control and Treatment (REACT): findings from a national Web-based survey. J Allergy Clin Immunol 119: $1454-1461$.

Polley DJ, Mihara K, Ramachandran R, Vliagoftis H, Renaux B, Saifeddine M, et al. (2017). Cockroach allergen serine proteinases: Isolation, sequencing and signalling via proteinase-activated receptor-2. Clin Exp Allergy 47: 946-960.

Pulimood TB, Corden JM, Bryden C, Sharples L, \& Nasser SM (2007). Epidemic asthma and the role of the fungal mold Alternaria alternata. J Allergy Clin Immunol 120: 610-617.

Ramachandran R, \& Hollenberg MD (2008). Proteinases and signalling: pathophysiological and therapeutic implications via PARs and more. Br J Pharmacol 153 Suppl 1: S263-282.

Ramachandran R, Noorbakhsh F, Defea K, \& Hollenberg MD (2012). Targeting proteinase-activated receptors: therapeutic potential and challenges. Nat Rev Drug Discov 11: 69-86.

Rayees S, Joshi JC, Tauseef M, Anwar M, Baweja S, Rochford I, et al. (2019). PAR2-Mediated cAMP Generation Suppresses TRPV4-Dependent $\mathrm{Ca}(2+)$ Signaling in Alveolar Macrophages to Resolve TLR4Induced Inflammation. Cell Rep 27: 793-805.e794.

Shrestha Palikhe N, Nahirney D, Laratta C, Gandhi VD, Vethanayagam D, Bhutani M, et al. (2015). Increased Protease-Activated Receptor-2 (PAR-2) Expression on CD14++CD16+ Peripheral Blood Monocytes of Patients with Severe Asthma. PLoS One 10: e0144500.

Snelgrove RJ, Gregory LG, Peiro T, Akthar S, Campbell GA, Walker SA, et al. (2014). Alternaria-derived serine protease activity drives IL-33 mediated asthma exacerbations. J Allergy Clin Immunol: 583-592. 
Stephenson KE, Neubauer GH, Bricault CA, Shields J, Bayne M, Reimer U, et al. (2016). Antibody Responses After Analytic Treatment Interruption in Human Immunodeficiency Virus-1-Infected Individuals on Early Initiated Antiretroviral Therapy. Open Forum Infect Dis 3: ofw100.

Stewart GA, Thompson PJ, \& Simpson RJ (1989). Protease antigens from house dust mite. Lancet 2: 154-155.

Sudha VT, Arora N, Gaur SN, Pasha S, \& Singh BP (2008). Identification of a serine protease as a major allergen (Per a 10) of Periplaneta americana. Allergy 63: 768-776.

Suen JY, Barry GD, Lohman RJ, Halili MA, Cotterell AJ, Le GT, et al. (2012). Modulating human proteinase activated receptor 2 with a novel antagonist (GB88) and agonist (GB110). British journal of pharmacology 165: 1413-1423.

Suen JY, Cotterell A, Lohman RJ, Lim J, Han A, Yau MK, et al.(2014). Pathway-selective antagonism of proteinase activated receptor 2. British journal of pharmacology 171: 4112-4124.

Sun G, Stacey MA, Schmidt M, Mori L, \& Mattoli S (2001). Interaction of mite allergens Der p3 and Der p9 with protease-activated receptor-2 expressed by lung epithelial cells. J Immunol 167: 1014-1021.

To T, Stanojevic S, Moores G, Gershon AS, Bateman ED, Cruz AA, et al. (2012). Global asthma prevalence in adults: findings from the cross-sectional world health survey. BMC Public Health 12: 204.

Wardlaw AJ (1999). Molecular basis for selective eosinophil trafficking in asthma: A multistep paradigm. J Allergy Clin Immunol 104:917-926.

Yau MK, Lim J, Liu L, \& Fairlie DP (2016). Protease activated receptor 2 (PAR2) modulators: a patent review (2010-2015). Expert Opin Ther Pat 26: 471-483.

Yau MK, Liu L, \& Fairlie DP (2013). Toward Drugs for Protease-Activated Receptor 2 (PAR2). J Med Chem 56: 7447-7497.

Yee MC, Nichols HL, Polley D, Saifeddine M, Pal K, Lee K, et al.(2018). Protease-activated Receptor-2 Signaling through beta-Arrestin-2 Mediates Alternaria Alkaline Serine Protease-induced Airway Inflammation. Am J Physiol Lung Cell Mol Physiol 315:L1042-L1057.

Zeldin DC, Wohlford-Lenane C, Chulada P, Bradbury JA, Scarborough PE, Roggli V, et al. (2001). Airway Inflammation and Responsiveness in Prostaglandin H Synthase-Deficient Mice Exposed to Bacterial Lipopolysaccharide. American Journal of Respiratory Cell and Molecular Biology 25: 457-465. 
Figure 1
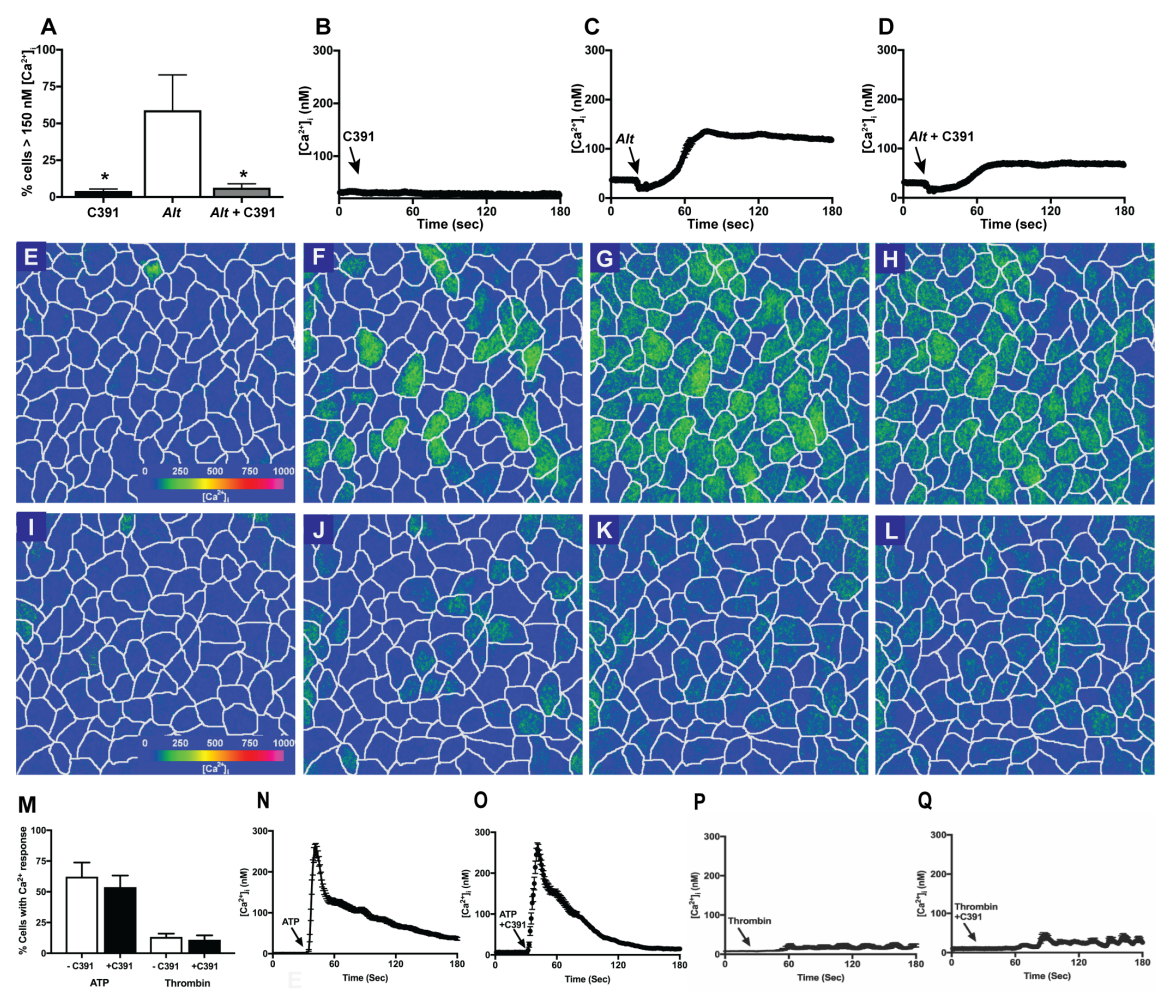


\section{Figure 2}

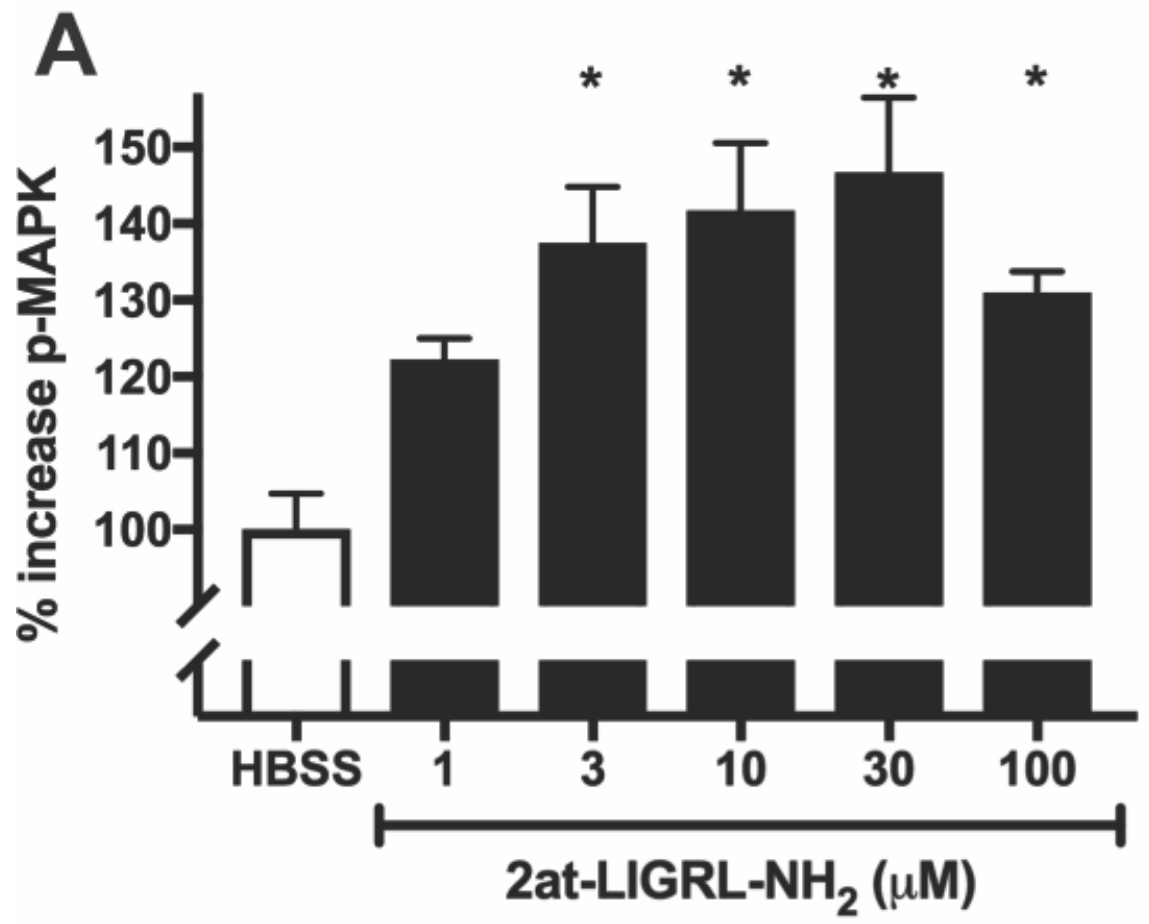

B

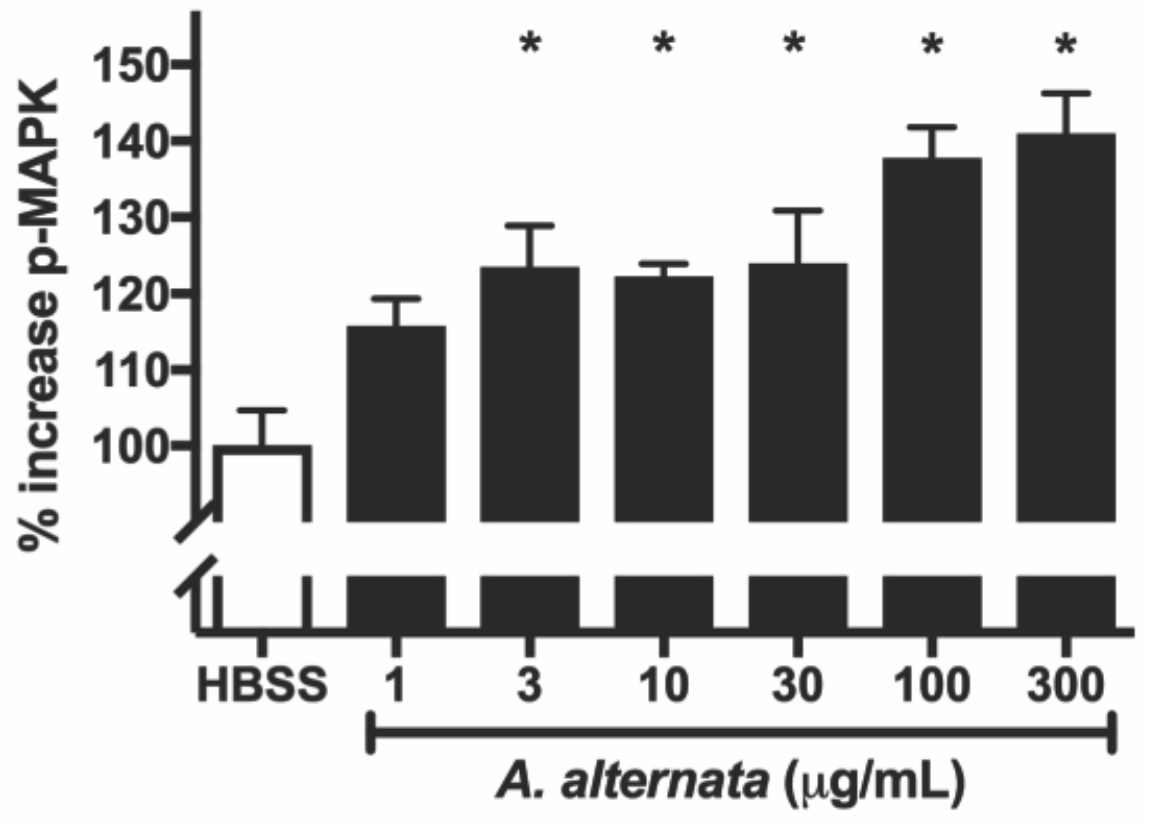

C

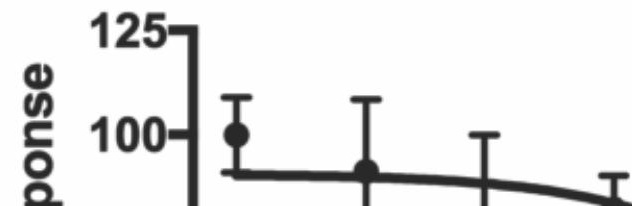


Figure 3

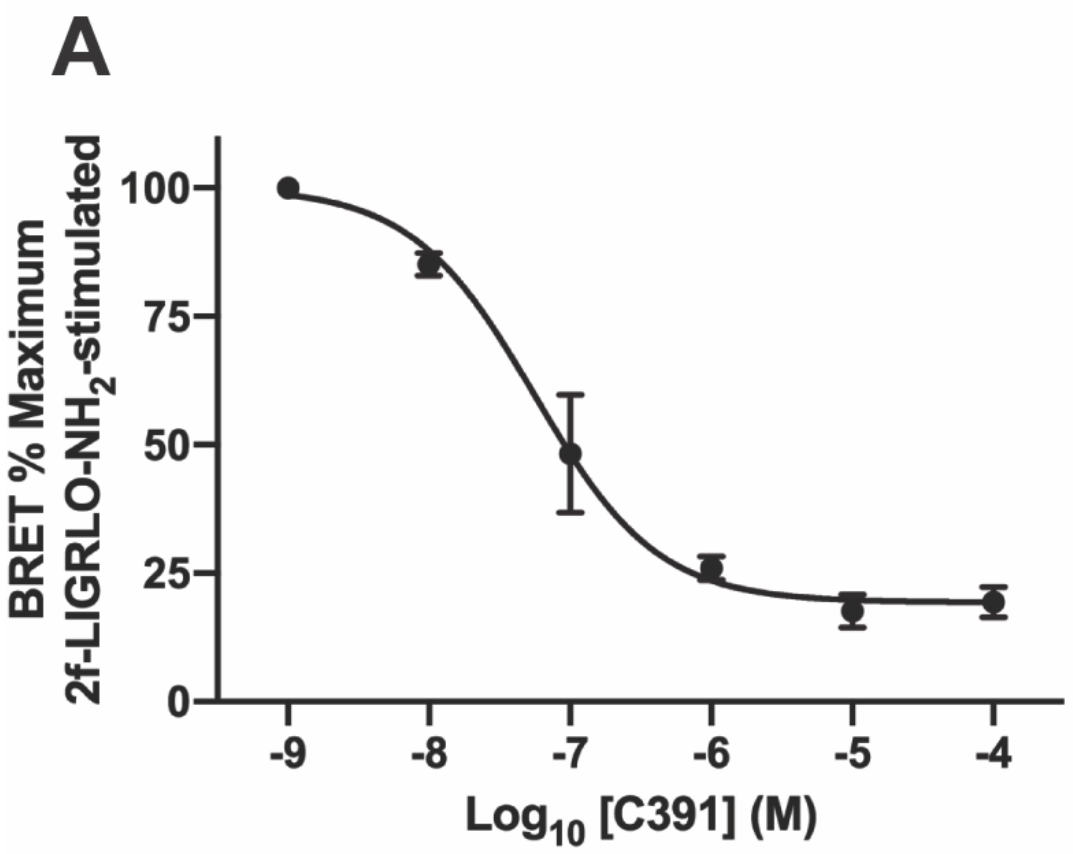

B

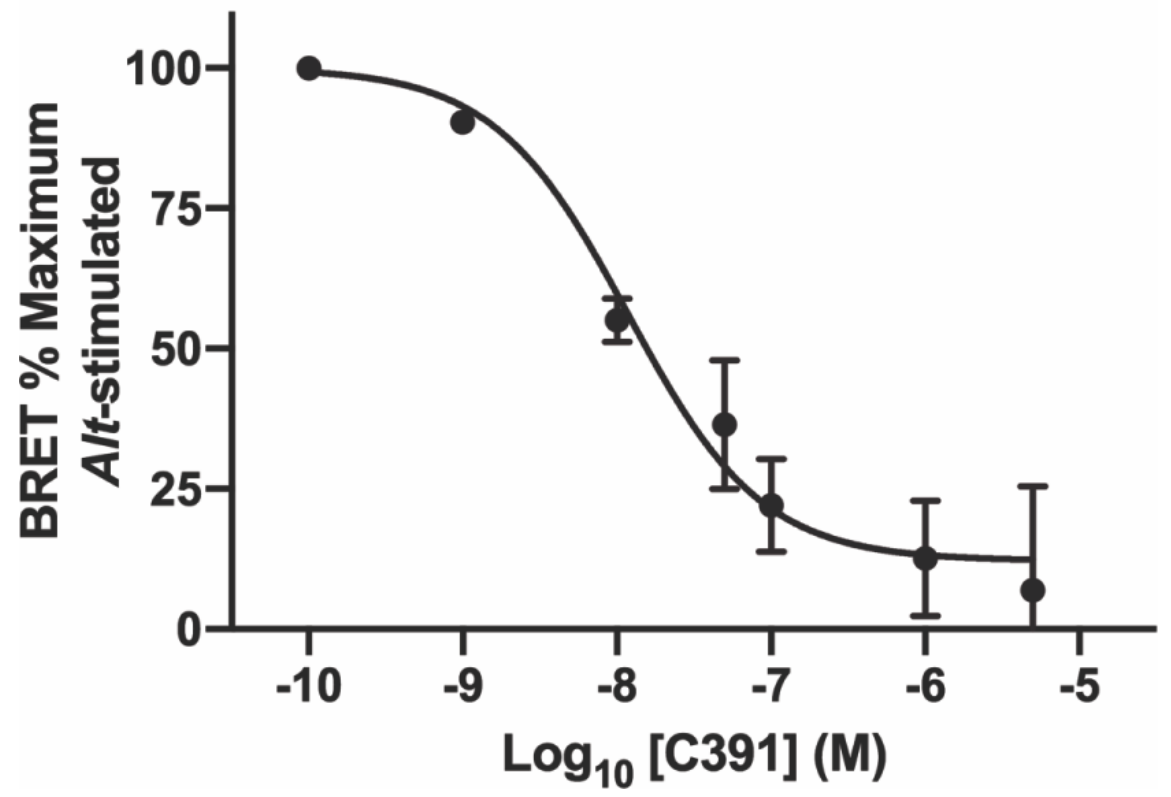


Figure 4

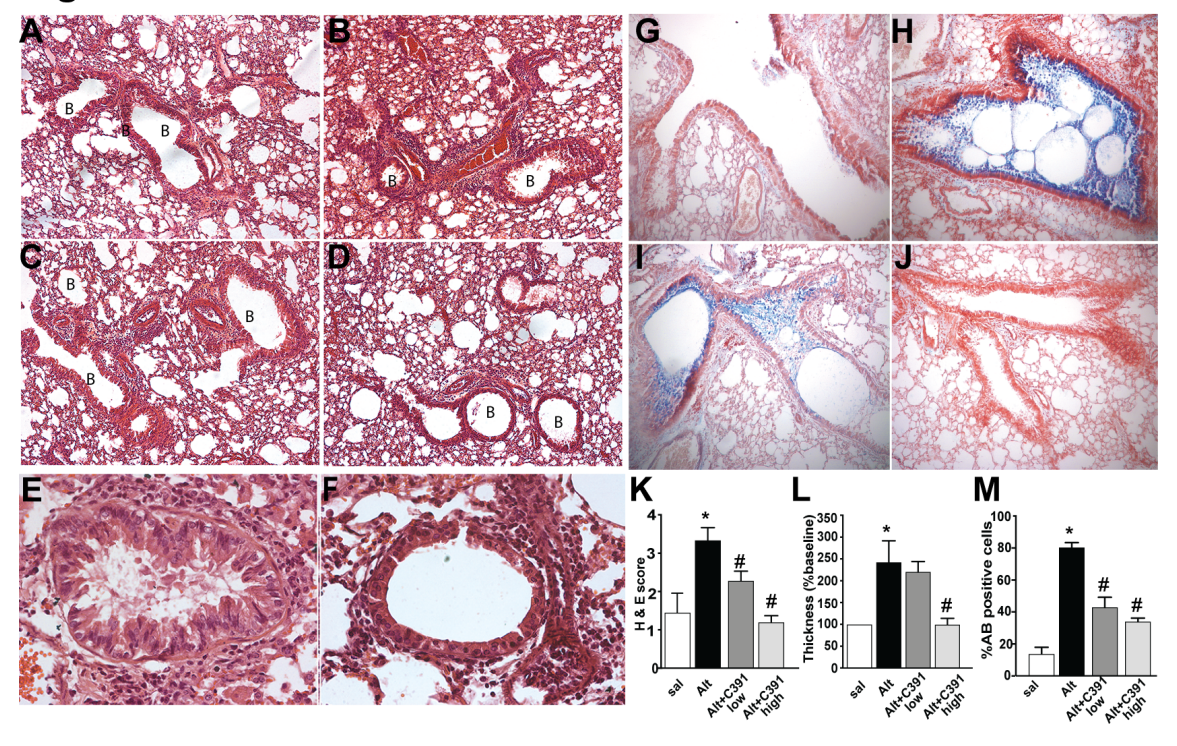




\section{Figure 5}
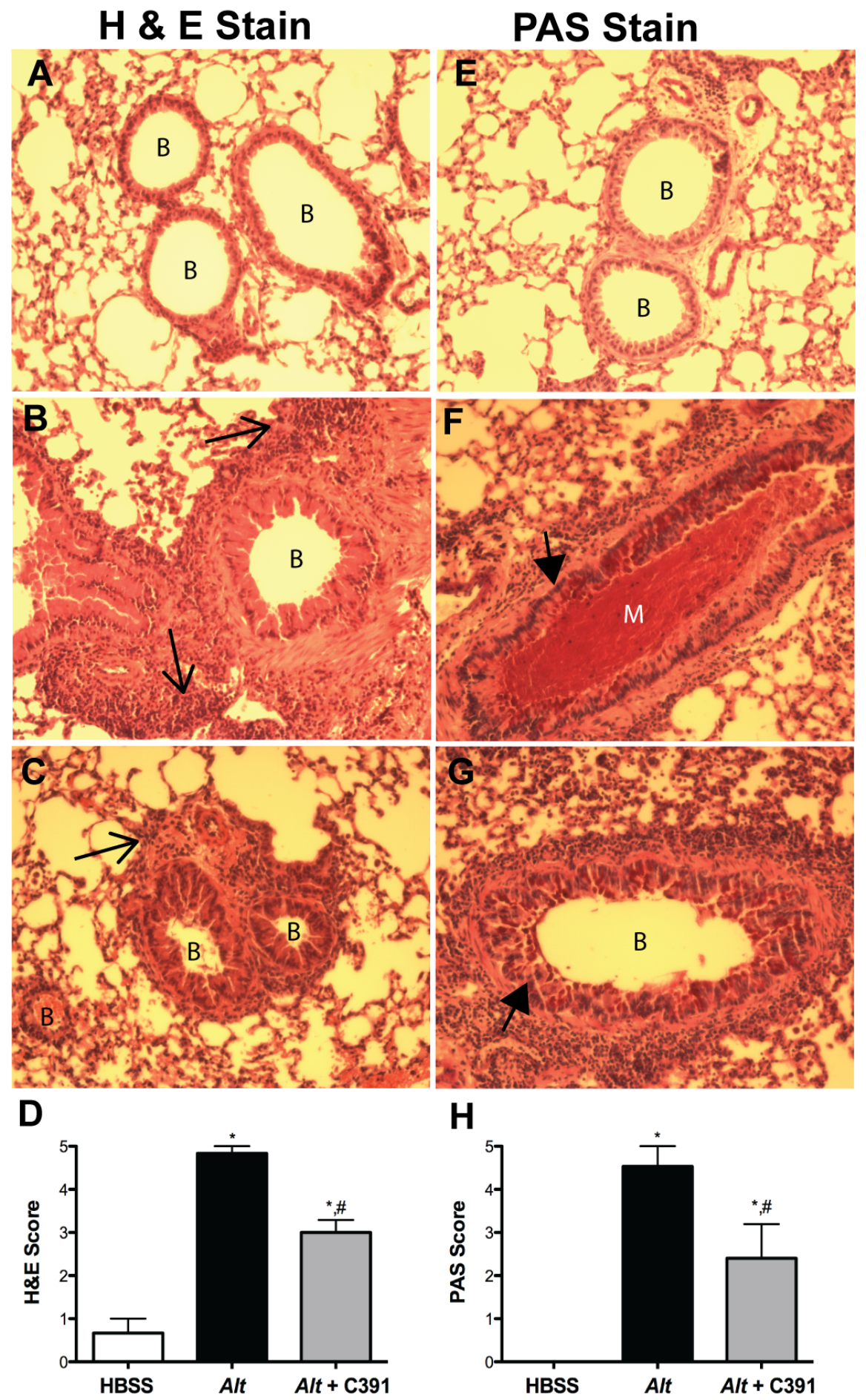
Figure 6
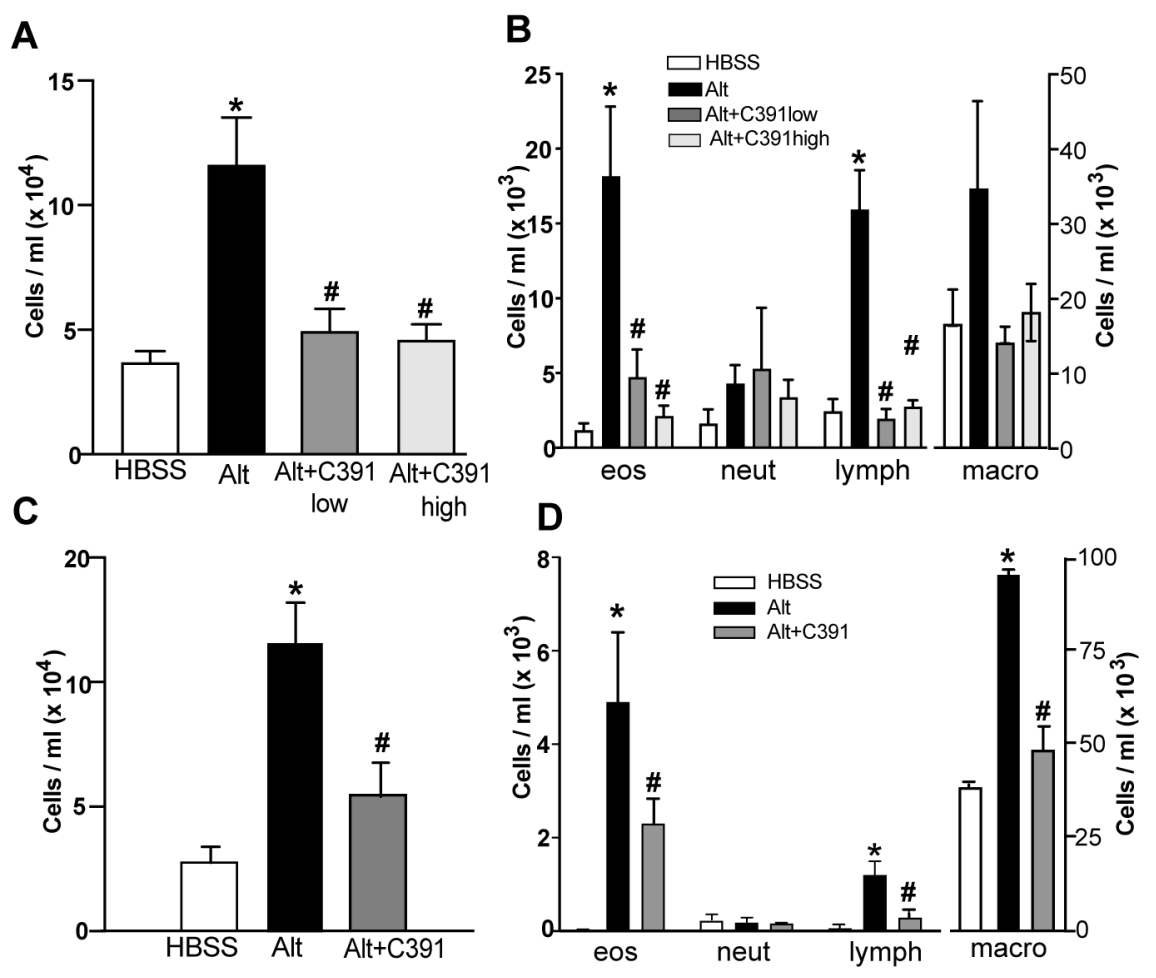

Figure 7

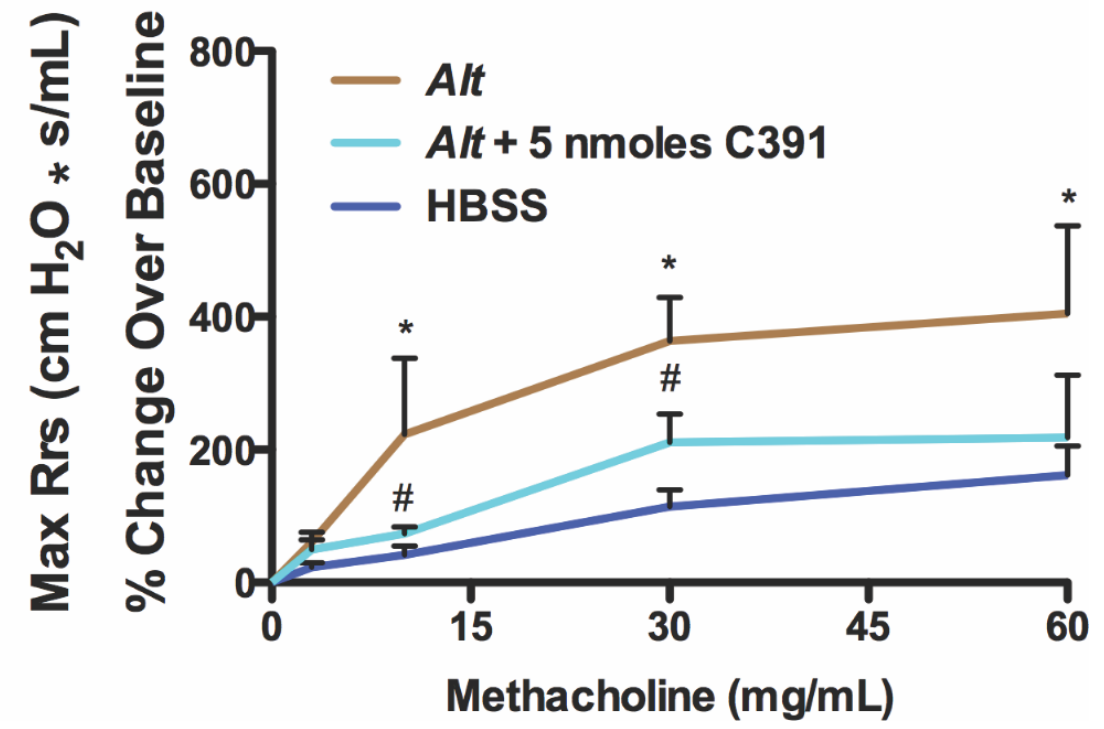

